\title{
Recent Developments in Asymmetric Hydrogenation and Transfer Hydrogenation of Ketones and Imines through Dynamic Kinetic Resolution
}

\author{
Pierre-Georges Echeverria \\ Tahar Ayad \\ Phannarath Phansavath* \\ Virginie Ratovelomanana-Vidal*
}

PSL Research University, Chimie ParisTech - CNRS, Institut de Recherche de Chimie Paris, 75005 Paris, France phannarath.phansavath@chimie-paristech.fr virginie.vida@chimie-paristech.fr

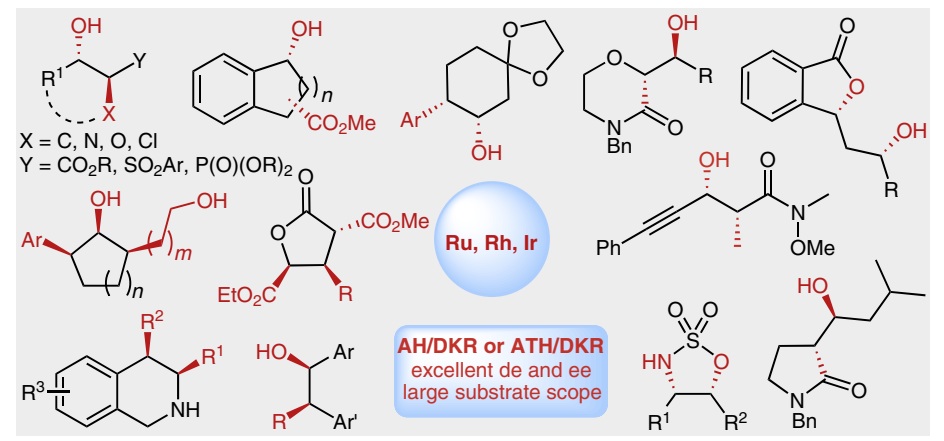

Received: 21.03.2016

Accepted after revision: 18.04.2016

Published online: 07.06 .2016

DOI: 10.1055/s-0035-1561648; Art ID: ss-2016-m0204-sr

Abstract The transition-metal-catalyzed asymmetric transfer hydrogenation (ATH) and asymmetric hydrogenation (AH) of $\alpha$ - and $\beta$-substituted ketone or imine derivatives are efficient methods for accessing chiral alcohols or amines bearing up to three stereogenic centers through a dynamic kinetic resolution (DKR) process. This review provides a summary of recent work in this field, focusing on the development of new catalytic systems and on the extension of these asymmetric reductions to new classes of substrates.

1 Introduction

2 Asymmetric Hydrogenation via Dynamic Kinetic Resolution

$2.1 \alpha$-Substituted Ketones

2.2. $\alpha$-Substituted $\beta$-Keto Esters and Amides

$2.3 \alpha$-Substituted $\beta$-Keto Phosphonates and Sulfones

$2.4 \alpha, \alpha^{\prime}$-Disubstituted Cyclic Ketones

$2.5 \alpha, \beta$-Disubstituted Cyclic Ketones

2.6 Imine Derivatives

3 Asymmetric Transfer Hydrogenation via Dynamic Kinetic Resolution

3.1 $\alpha$-Substituted $\beta$-Diketones and Ketones

3.2 $\alpha$-Substituted $\beta$-Keto Esters, Amides and Phosphonates

3.3 $\beta$-Substituted $\alpha$-Keto Esters and Phosphonates

$3.4 \beta$-Substituted $\gamma$-Keto Esters

3.5 B-Alkoxy Ketones

3.6 Imine Derivatives

4 Conclusion

Key words asymmetric hydrogenation, asymmetric transfer hydrogenation, dynamic kinetic resolution, chiral alcohols, chiral amines, stereoselectivity, ketones, imines

\section{Introduction}

Because chirality is present in many natural products, the importance of asymmetric synthesis is now indubitable. Moreover, this concept of chirality is directly linked to the biological activity of drugs. Therefore, discovering and de- veloping new asymmetric reactions is of critical importance to organic synthesis. ${ }^{1}$

Amongst stereoselective reactions, the asymmetric reduction of unsaturated compounds is the most fundamental means of introducing chirality in organic compounds. ${ }^{2}$ Two of these transformations, transition-metal-catalyzed asymmetric hydrogenation $(\mathrm{AH})^{3}$ and asymmetric transfer hydrogenation (ATH), ${ }^{4}$ are powerful methods of producing optically enriched compounds, and have been shown to be useful in large-scale applications for the synthesis of fine chemicals and pharmaceuticals. ${ }^{5}$ Furthermore, the combination of both methods with a dynamic kinetic resolution (DKR) process allows a highly efficient route to chiral compounds bearing two or more stereogenic centers.

In a DKR process, the kinetic resolution step proceeds with an in situ racemization and consequently the substrate can be totally converted into a single product with a $100 \%$ theoretical yield. Therefore, under DKR conditions, the $\mathrm{AH}$ or ATH of a substrate possessing a labile stereocenter allows the enantioselective synthesis of one diastereomer. To achieve efficient DKR, Curtin-Hammett kinetic conditions must be fulfilled: the rate of racemization $\left(k_{\mathrm{rac}}\right)$ of the starting material has to be faster than the rate of the asymmetric transformation $\left(k_{1}\right.$ and $\left.k_{2}\right)$ and one enantiomer must react faster than the other one $\left(k_{1}>k_{2}\right.$ or $\left.k_{2}>k_{1}\right)$. Furthermore, the asymmetric reaction has to be irreversible, i.e., the product formed during the reaction has to be stable to avoid any racemization (Scheme 1 ).

This review updates major advances from 2011 to February 2016 in the field of transition-metal-catalyzed DKR using $\mathrm{AH}$ and ATH applied to ketones and imines. Several comprehensive reviews covering this topic have been previously published. ${ }^{6}$ The structures of the ligands and complexes described in this review are shown in Figure 1 and Figure 2, respectively. 


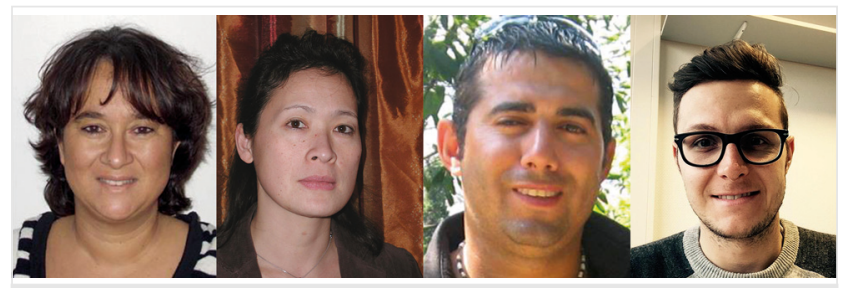

Virginie Vidal (left) received her Ph.D. from Paris-Sud University under the supervision of Professor H. P. Husson and Dr. J. Royer (Gif, France). She then pursued postdoctoral appointments with Professor S. Hanessian (Montreal University, Canada, 1989-1990), and Professor P. Potier and Dr. R. H. Dodd (Gif, 1991). She was appointed as a CNRS Associate Researcher with Professor. J.-P. Genêt at Ecole Nationale Supérieure de Chimie de Paris. She is currently CNRS Research Director at Chimie ParisTech (Paris, France). Her research interests focus on transitionmetal catalysis and metallo-organocatalysis for atom- and step-economical reactions and the design of atropisomeric ligands (Synphos and Difluorphos) for asymmetric catalysis. The synthesis of biorelevant targets is also a focus in her group. She was Chair of the Division of Organic Chemistry of the French Chemical Society (2009-2012).

Phannarath Phansavath (second from left) was born in Vientiane (Laos). She received her Ph.D. from Pierre and Marie Curie University in 1997 under the supervision of Professor M. Malacria and $\operatorname{Dr}$ C. Aubert. After postdoctoral studies in the group of Professor C. Bolm at the Institut für Organische Chemie, RWTH Aachen (Germany), she was appointed assistant professor in 1999 in the group of Professor J.-P. Genêt at Ecole Nationale Supérieure de Chimie de Paris (Chimie ParisTech). Her current research interests include total synthesis of biologically relevant natural products and transition-metal-catalyzed asymmetric reactions. Tahar Ayad (second from right) was born in Saint-Etienne (France). He received his Ph.D. degree (2003) from the University of Toulouse under the supervision of Dr. Y. Génisson and Dr. M. Baltas, working on the total synthesis of imino sugars that exhibit antituberculosis activity. After his Ph.D., he was engaged in a postdoctoral position with Professor Robert S. Coleman at The Ohio State University working on the total synthesis of oximidin I and II. After a brief period spent at Toulouse University working as an associate professor in R. Chauvin's group in 2005, he joined the group led by Professor J.-P. Genêt and Dr. V. Vidal at the Ecole Nationale Supérieure de Paris, Chimie ParisTech. His present research fields include ligand synthesis, transition-metal-catalyzed asymmetric reactions and the synthesis of biologically relevant active compounds.

Pierre-Georges Echeverria (right) was born in 1987 in France. He graduated from the engineering school ENSIACET (Toulouse, France) in 2011. He moved to ENSCP Chimie ParisTech to continue his education under the supervision of Dr. Phannarath Phansavath and Dr. Virginie Vidal, earning his Ph.D. in 2014. During this time, his research focused on the total synthesis of mirabalin and the development of different methodologies to control amino alcohol moieties by asymmetric reduction. In 2015, he joined the group of Professor Alois Fürstner at the Max-Planck-Institut für Kohlenforschung as a postdoctoral fellow working on iron catalysis. He is currently an R\&D scientist at Minakem.

\section{Asymmetric Hydrogenation via Dynamic Kinetic Resolution}

The first example of asymmetric reduction coupled with a DKR was reported by Tai in 1979 with the heterogeneous hydrogenation of $\alpha$-substituted- $\beta$-keto esters, catalyzed by Raney-Nickel modified by $(R, R)$-tartaric acid, yield-

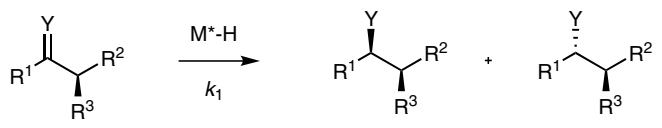

$$
\begin{aligned}
& \mathrm{Y}=\mathrm{O}, \mathrm{NH} \quad \text { conditions for an efficient dynamic kinetic resolution: } \\
& k_{\text {rac }} \| \quad \begin{array}{l}
* k_{\text {rac }}>k_{1}, k_{2} \\
* k_{1}>k_{2} \text { or } k_{2}>k_{1} \\
* \text { high }
\end{array} \\
& \begin{array}{l}
k_{1}>k_{2} \text { or } k_{2}>k_{1} \\
\text { high enantiofacial discrimination of the catalyst }
\end{array}
\end{aligned}
$$

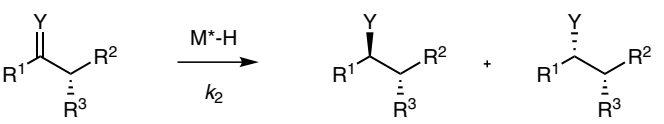

Scheme 1

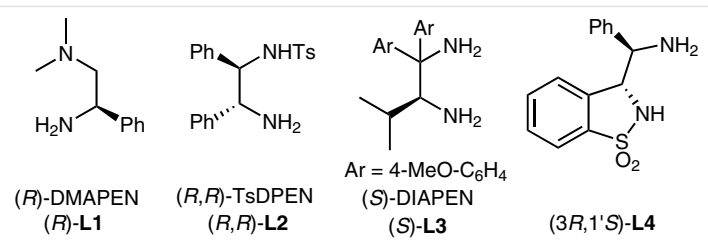

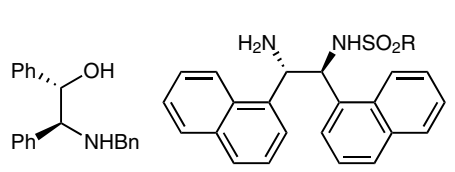

$(S, S)-B n D P A E$ $(S, S)$-L5

$(S, S)-\mathbf{L 6}: \mathrm{R}=2,6-\mathrm{Ph}_{2} \mathrm{C}_{6} \mathrm{H}_{3}$

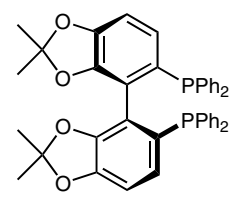

(S)-SunPhos (S)-L9 ing the reduced product as a 78:22 syn/anti mixture with a $57 \%$ ee for the syn isomer. ${ }^{7}$ In 1989 , the pioneering work of Noyori $^{8}$ and that of Genêt and co-workers ${ }^{9}$ led to the first examples of homogeneous enantioselective rutheniumpromoted hydrogenations of racemic $\alpha$-acetamido $\beta$-keto esters via dynamic kinetic resolution using, respectively, BINAP-Ru(II) and CHIRAPHOSRu(II) catalysts (Scheme 2). The hydrogenation reaction of racemic 2-acylamino-3oxobutyrate provided the corresponding syn $\mathrm{L}$ - and D-threonine derivatives with high levels of enantioselectivity (up to $98 \%$ ee) and diastereoselectivity (syn/anti up to 99:1).

Thereafter, Noyori and co-workers published extensively on asymmetric hydrogenation via DKR of $\alpha$-substituted $\beta$-keto esters, including stereochemical models ${ }^{6 a}$ and $a$ mathematical analysis of the kinetics of the DKR, marking an important breakthrough in this area. ${ }^{10,11}$ Numerous authors have subsequently made important contributions to 


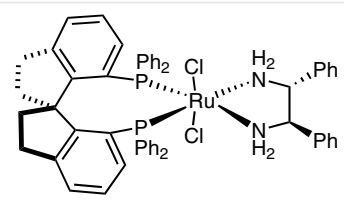

$\left(S_{a}, R, R\right)$-CAT1

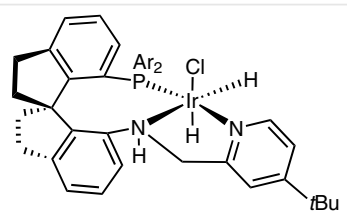

(R)-CAT2 $\left(\mathrm{Ar}=3,5\right.$-di-tBu- $\left.\mathrm{C}_{6} \mathrm{H}_{3}\right)$

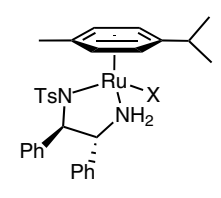

$(R, R)$-СAT3 (X = OTf) $(R, R)$-CAT4 $(\mathrm{X}=\mathrm{Cl})$

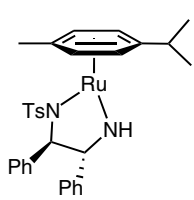

$(R, R)$-CAT8

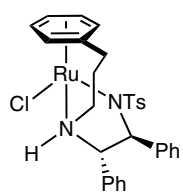
(S,S)-CAT12

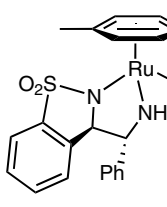

$(R, R)$-CAT5

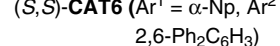

$(S, S)$-CAT7 $\left(\mathrm{Ar}^{1}=\mathrm{Ph}, \mathrm{Ar}^{2}=\mathrm{C}_{6} \mathrm{~F}_{5}\right)$

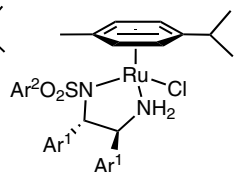

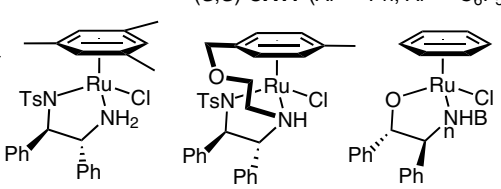

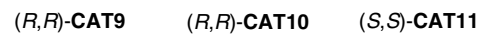

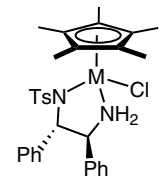

(S,S)-CAT13 $(\mathrm{M}=\mathrm{Ir})$ $(S, S)$-CAT14 $(\mathrm{M}=\mathrm{Rh})$

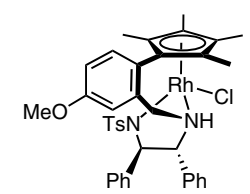

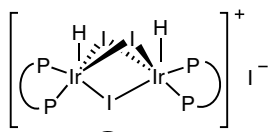
CAT16 $(\overparen{P P}=$ Synphos $)$

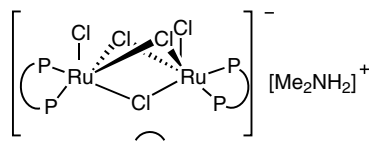

CAT17 $(\overparen{P P}=$ Synphos $)$

Figure 2

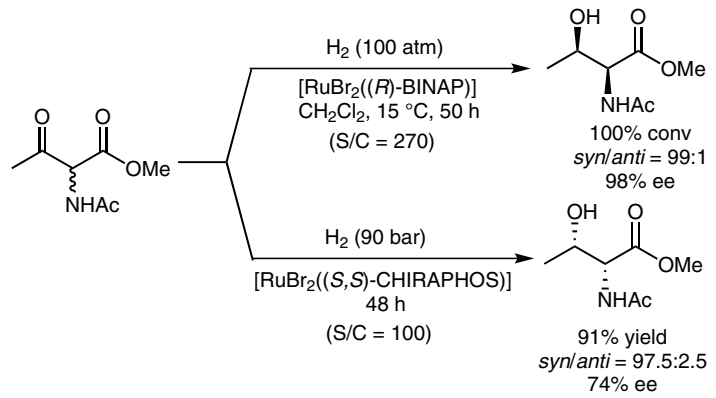

Scheme 2

this field of research and they include, but are not limited to, asymmetric hydrogenation via DKR of non-activated ketones, ${ }^{12}$ organocatalyzed DKR ${ }^{13}$ and enzymatic DKR. ${ }^{14}$

\section{$2.1 \quad \alpha$-Substituted Ketones}

In 2011, Ohkuma and co-workers reported the asymmetric hydrogenation of various aryl heterocycloalkyl ketones through DKR using $\left[\mathrm{RuCl}_{2}((S)\right.$-Binap $)((R)$-DMAPEN $\left.)\right]$ as the catalyst (Scheme 3). ${ }^{15}$ Under optimized reaction conditions, the corresponding alcohols were efficiently produced in $95-100 \%$ yields with good to excellent diastereoselectivities (>99:1) and ee values ranging from $94-99 \%$. The authors noted that the diastereoselectivity of the reaction was essentially controlled by the nature of the $\mathrm{X}$ group present on the heterocyclic rings. Specifically, high syn selectivities were obtained for the hydrogenation of ketones with $\mathrm{X}=\mathrm{O}$ or $\mathrm{X}=\mathrm{CH}_{2}$, whereas high anti selectivities were observed for substrates having a bulkier NBz or NBoc substituent. The authors also showed that such a reaction could be performed with a very low catalyst loading $(\mathrm{S} / \mathrm{C}=$ 20000) without affecting the catalytic efficiency. This method was successfully applied to the synthesis of $(S, S)$ reboxetine succinate, a selective norepinephrine uptake inhibitor.

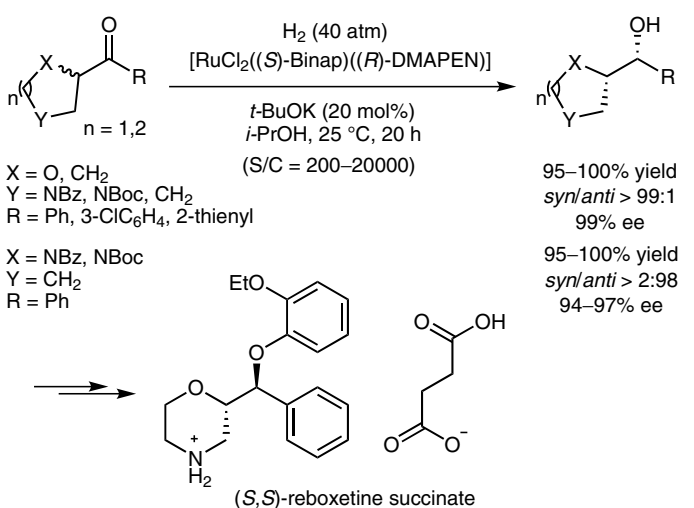

Scheme 3

In the course of the synthesis of a new glucagon receptor antagonist drug candidate for the treatment of type 2 diabetes, scientists from Merck Research Laboratories developed, in 2012, a robust and highly efficient route using an asymmetric hydrogenation reaction combined with DKR as a key step to install the two adjacent tertiary stereogenic centers (Scheme 4). ${ }^{16}$ After intensive experiments, the $\mathrm{RuCl}_{2}(S)$-xyl-Segphos/(S)-DIAPEN complex was identified as the optimum catalyst for this transformation giving the targeted reduced alcohol in 94\% yield with excellent diastereoselectivity (anti/syn >99:1) and high enantioselectivity $(>98.5 \%)$. Furthermore, this reaction was performed efficiently on a multikilogram scale with a relatively low catalyst loading $(\mathrm{S} / \mathrm{C}=5000)$.

In 2012, Zhou and co-workers described a highly enantio- and diastereoselective ruthenium-catalyzed hydrogenation of racemic $\alpha$-arylcyclohexanones through DKR by using a chiral (diamine)(spirodiphosphine)ruthenium(II) chloride complex as the catalyst (Scheme 5 ). ${ }^{17}$ Under optimized reaction conditions, a series of enantiomerically enriched $\alpha$-arylcyclohexanols was obtained in $68-98 \%$ yield with excellent cis selectivities (cis/trans >99:1) and enan- 


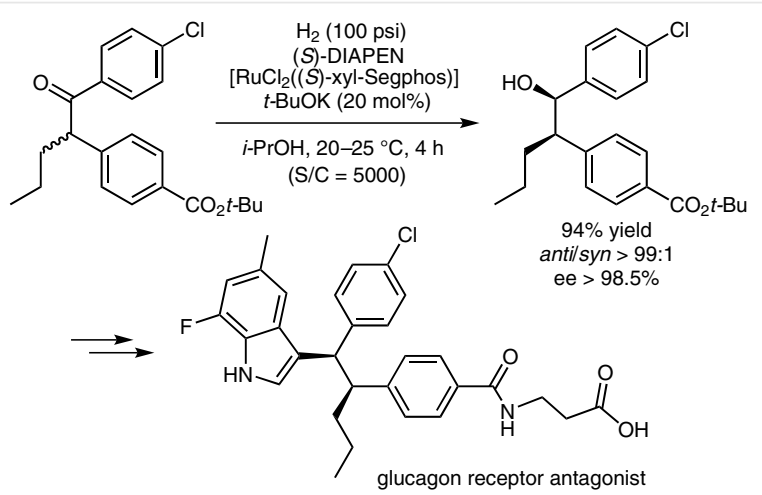

Scheme 4

tioselectivities ranging from $57 \%$ to $99 \%$ by employing $\left(S_{a}, R, R\right)$-CAT1 as a precatalyst. It must be noted, however, that substrates bearing ortho-substituents afforded products in lower yields and ee values. As shown in Scheme 5, the usefulness of these enantiopure $\alpha$-arylcyclohexanols was also demonstrated by the synthesis of several biologically active molecules such as (-)- $\alpha$-lycorane, (-)-CP 55940 and tetrahydrocannabinol derivatives.
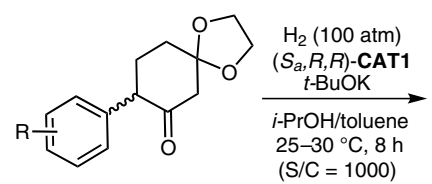

$\mathrm{R}=3,4-\mathrm{O}\left(\mathrm{CH}_{2}\right) \mathrm{O}, \mathrm{H}, 4-\mathrm{Me}$,

4- $\mathrm{MeO}, 4-\mathrm{CF}_{3}$, 3-Me, 3-MeO

2-Me, 2-MeO, 3,4-(MeO)

$3,4-\mathrm{O}\left(\mathrm{CH}_{2}\right) \mathrm{O}-5-\mathrm{MeO}$
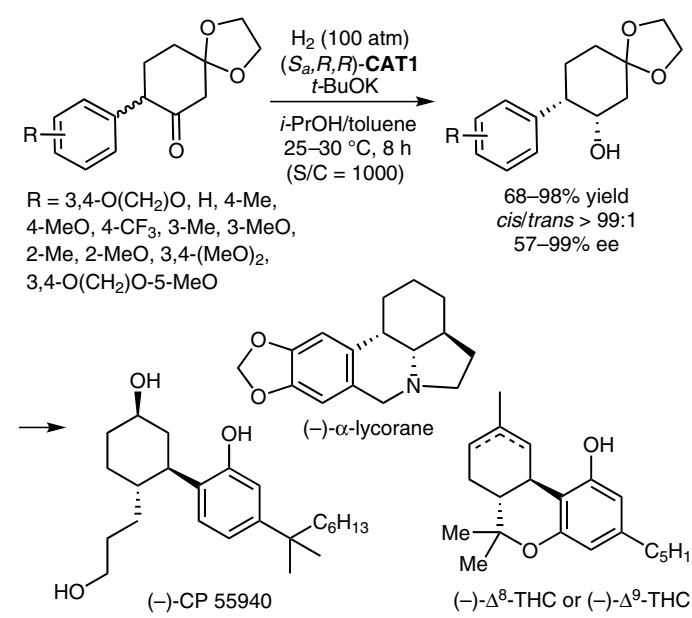

trans > 99:

Scheme 5

The same group further extended the above-mentioned method for the enantioselective synthesis of (-)-galanthamine and (-)-lycoramine, two alkaloids that have been used clinically as selective acetylcholinesterase inhibitors for the treatment of Alzheimer's disease (Scheme 6). ${ }^{18}$ In this case, the synthetic route featured ruthenium-catalyzed asymmetric hydrogenation via DKR of a racemic $\alpha$-aryloxy cyclic ketone, producing the key chiral $\beta$-aryloxy cyclohexanol intermediate in $99 \%$ yield with up to $97 \%$ ee and $>99: 1$ cis/trans selectivity.
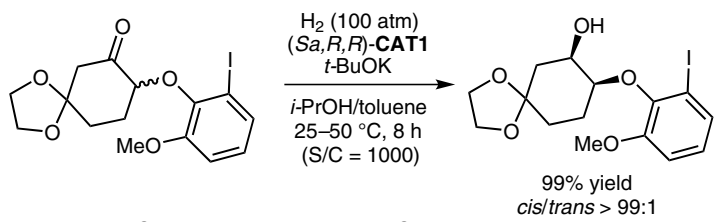

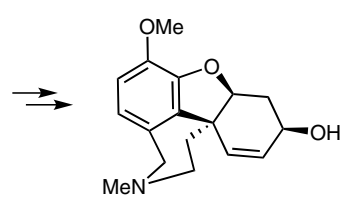

(-)-galanthamine

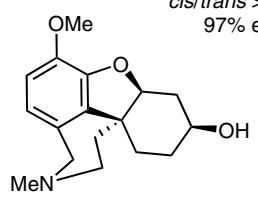

(-)-lycoramine

\section{Scheme 6}

Neolignans are the most abundant natural products found in several families of plants. These molecules exhibit a wide range of biological properties and feature a common 2-aryl-2,3-dihydrobenzofuran skeleton. In 2013, Chen and co-worker developed a concise and straightforward access to this family of compounds based on the asymmetric hydrogenation of racemic ketones under DKR conditions (Scheme 7). ${ }^{19}$ A screening of reaction parameters revealed that the use of $0.1 \mathrm{~mol} \%$ of $\left[\mathrm{RuCl}_{2}((S)\right.$-xyl-Segphos $)((S)$-DIAPEN)] as the catalyst in the presence of $t$-BuOK facilitated epimerization, resulting in the formation of the chiral carbinol key intermediate with nearly perfect selectivity (99.1\% ee, >50:1 dr) and excellent yield (95\%). This protocol has been applied to the synthesis of $(+)$-conocarpan as well as other members of the neolignan family.

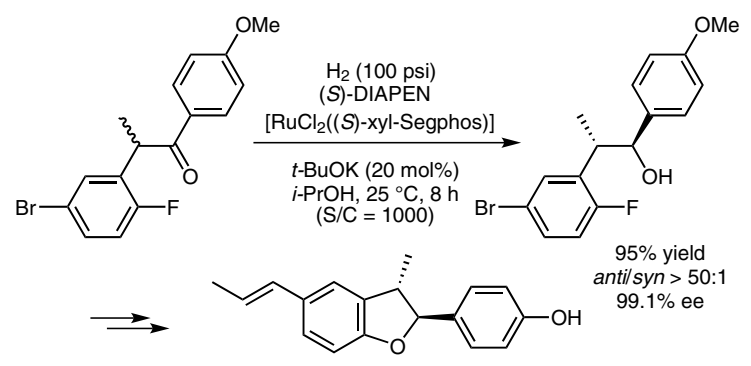

(+)-conocarpan

Scheme 7

\section{$2.2 \alpha$-Substituted $\beta$-Keto Esters and Amides}

Continuing a long-established interest in metal-catalyzed reductions/DKR, ${ }^{6 f, 20}$ our group used the key step of asymmetric hydrogenation to achieve a short and efficient total synthesis of the naturally occurring bioactive ceramide symbioramide starting from readily accessible racemic $\alpha$-amino and $\alpha$-amido $\beta$-keto esters (Scheme 8 ). Application of the $\mathrm{Ru}$ (II)-SYNPHOS-catalyzed asymmetric hydrogenation reaction to both racemic $\alpha$-amino and $\alpha$-amido $\beta$ keto ester derivatives enabled, through a dynamic kinetic resolution process, the preparation of the corresponding 
anti and syn amino alcohols in high enantio- and diastereoselectivities (up to $98 \%$ de and $98 \%$ ee). This flexible strategy also provided an efficient access to structural isomers of symbioramide, which were prepared with high asymmetric inductions. $^{21}$
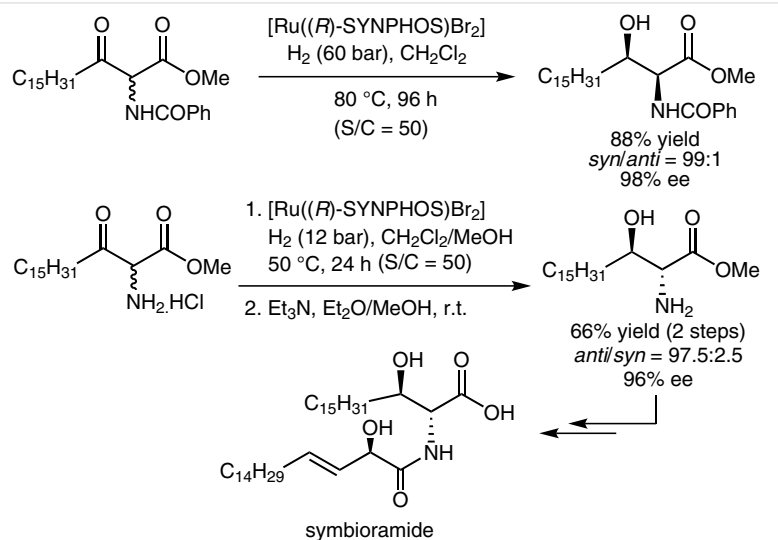

Scheme 8

Pioneering work on the hydrogenation of $\alpha$-amino $\beta$ keto ester hydrochlorides associated with a DKR process was reported in 2004 by Hamada ${ }^{22}$ and our group. ${ }^{20 d, e, g}$ In 2014 , we accomplished the AH/DKR transformation of $\alpha$ amino $\beta$-keto ester hydrochlorides using a cationic dinuclear iridium(III) complex incorporating an in-house-developed SYNPHOS ligand (Scheme 9). ${ }^{23}$ The reaction allowed for the synthesis of a wide range of enantioenriched anti $\alpha-$ amino $\beta$-hydroxy ester hydrochloride derivatives containing alkyl, and electron-rich and electron-poor aryl groups. When subjected to the optimized hydrogenation conditions using $1.5 \mathrm{~mol} \%$ of the cationic dinuclear iridium(III) catalyst $\left[(\operatorname{Ir}(\mathrm{H})[(S)-S Y N P H O S])_{2}(\mu-I)_{3}\right] \mathrm{I}(\text { CAT16 })^{24}$ and NaOAc in acetic acid under 100 bar of hydrogen pressure at $40^{\circ} \mathrm{C}$, excellent anti diastereoselectivities (anti/syn up to 99:1) and enantioselectivities (up to $90 \%$ ee) were achieved. ${ }^{25}$

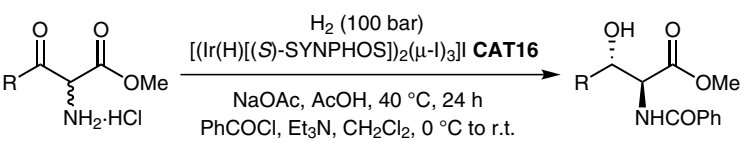

$$
\begin{aligned}
& \text { (S/C = 66) 58-87\% yield } \\
& \begin{array}{cc}
\text { 4- } \mathrm{MeC}_{6} \mathrm{H}_{4}, 4-\mathrm{MeOC}_{6} \mathrm{H}_{4}, 4-\mathrm{BrC}_{6} \mathrm{H}_{4}, & \text { antilsyn }=83: 17 \text { to } 99: 1 \\
62-90 \% \text { ee }
\end{array} \\
& \text { 4- } \mathrm{ClC}_{6} \mathrm{H}_{4}, 4-\mathrm{FC}_{6} \mathrm{H}_{4}, 2 \text {-thienyl, } \\
& \text { cyclohexyl, } \mathrm{C}_{15} \mathrm{H}_{31}
\end{aligned}
$$

Scheme 9

We successfully used the ruthenium-catalyzed dynamic kinetic resolution of racemic $\alpha$-amino $\beta$-keto ester hydrochlorides to access the C44-C65 fragment of mirabalin, a cytotoxic macrolide isolated in 2008 from the marine sponge, Siliquariaspongia mirabilis (Scheme 10). ${ }^{26}$ The hydrogenation reaction was carried out efficiently under mild conditions at $50{ }^{\circ} \mathrm{C}$ in $\mathrm{CH}_{2} \mathrm{Cl}_{2} / \mathrm{MeOH}$ using 13 bar of hydrogen pressure and $1 \mathrm{~mol} \%$ of the Ru-SYNPHOS catalyst $(R)$ CAT17 developed in our group. ${ }^{23 e}$ This operationally facile process, scaled to $25 \mathrm{~g}$, provided a ready access to the $\mathrm{N}$ protected anti amino alcohol in 92\% yield and with high levels of diastereo- and enantioinduction (97\% de, $98 \%$ ee).
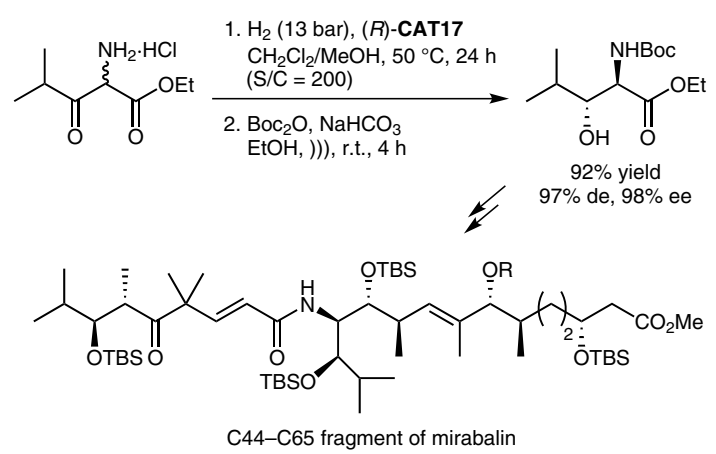

Scheme 10

Because serotonin norepinephrine reuptake inhibitors (SNRIs) have demonstrated efficiency in the treatment of pain, researchers from Eli Lilly established a stereoselective route to access pyrrolidine ether SNRIs based on enantioand diastereoselective DKR/hydrogenation of a $\beta$-keto- $\gamma$ lactam derivative (Scheme 11). ${ }^{27}$ A catalyst structure evaluation showed that high stereoinductions (96\% ee, 94\% de) were obtained using the $\left[\mathrm{Ru}(\mathrm{OAc})_{2}((S)\right.$-tol-BINAP) $]$ complex in isopropanol compared to ethanol or methanol with catalytic amounts of $\mathrm{HCl}(6 \mathrm{~mol} \%)$ and $\mathrm{LiCl}(1 \mathrm{~mol} \%)$ to increase the reactivity of the catalytic system. Interestingly, studies using online NMR and HPLC revealed that one enantiomer of the racemic $\beta$-keto- $\gamma$-lactam was hydrogenating faster than the interconversion between the enantiomers.
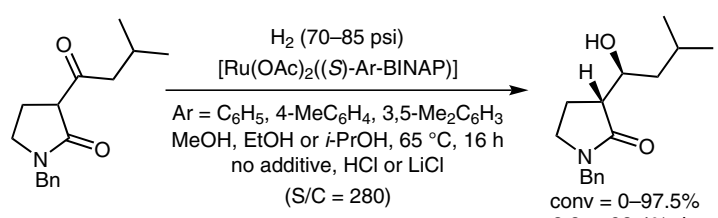

conv $=0-97.5 \%$ 8.8 to $98.4 \%$ de
$4.5-98.4 \%$ ee

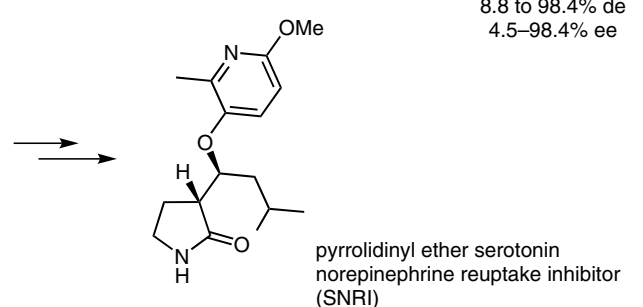
(SNRI)

Scheme 11

Zhang and co-workers described the enantio- and diastereoselective synthesis of $\beta^{\prime}$-hydroxy- $\beta$-amino acids using in situ generated $\left[\mathrm{RuCl}_{2}(p \text {-cymene })\right]_{2}-(S)-$ SunPhos as the 
catalyst for the asymmetric hydrogenation of $\beta$-keto- $\beta$ amino esters through DKR (Scheme 12). ${ }^{28}$ The highest levels of diastereo- (up to $98 \%$ de) and enantioinduction (up to 99.9\% ee) were obtained using dichloromethane/2,2,2-trifluoroethanol (TFE) or 1,2-dichloroethane/TFE combinations as solvents. The authors showed that the use of $\left[\mathrm{RuCl}_{2} \text { (p-cymene) }\right]_{2}-(S)$-SunPhos in these solvent mixtures was more efficient than $\left[\operatorname{RuI}_{2}(p \text {-cymene })\right]_{2}$ associated with common diphosphine ligands in $\mathrm{CH}_{2} \mathrm{Cl}_{2} / \mathrm{MeOH}$ or $\mathrm{CH}_{2} \mathrm{Cl}_{2} / \mathrm{EtOH}$.

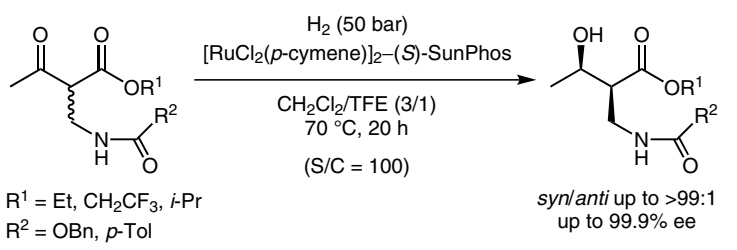

Scheme 12

\section{$2.3 \alpha$-Substituted $\beta$-Keto Phosphonates and Sul- fones}

Because of their prevalence in bioorganic and medicinal chemistry, and owing to their unique biological activities as well as their potential uses as peptide mimics, chiral $\beta$-hydroxy $\alpha$-amino phosphonates have received considerable attention in recent years. In 2013, Zhang and co-workers reported a convenient and general protocol for the synthesis of these compounds through Ru-catalyzed hydrogenation of $\alpha$-amido $\beta$-keto phosphonates via DKR (Scheme 13). ${ }^{29}$ By using [ $\mathrm{RuCl}$ (benzene)(S)-SunPhos]Cl as the catalyst, excellent levels of stereoselectivity were observed for the corresponding syn- $\alpha$-amido $\beta$-hydroxy phosphonates (up to 99:1 syn/anti, up to $99.8 \%$ ee). The authors demonstrated the crucial role of additives in the stereochemical outcome of the reaction, because a dramatic increase of both $\mathrm{dr}$ and ee was observed after the addition of $\mathrm{CeCl}_{3} \cdot 7 \mathrm{H}_{2} \mathrm{O}$.

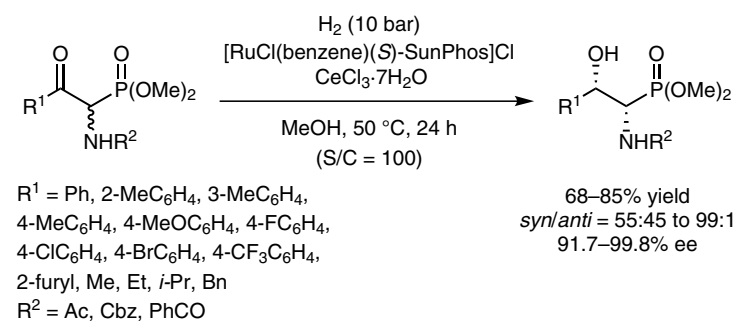

Scheme 13

The same group disclosed the asymmetric hydrogenation of $\alpha$-substituted $\beta$-keto phosphonates in the presence of $[\mathrm{RuCl}$ (benzene)(S)-SunPhos]Cl as the catalyst (Scheme 14). ${ }^{30}$ The corresponding syn- $\beta$-hydroxy phosphonates were obtained with excellent diastereo- and enantioselectivities (up to $96: 4$ syn/anti, up to $>99.8 \%$ ee) under optimized reaction conditions.

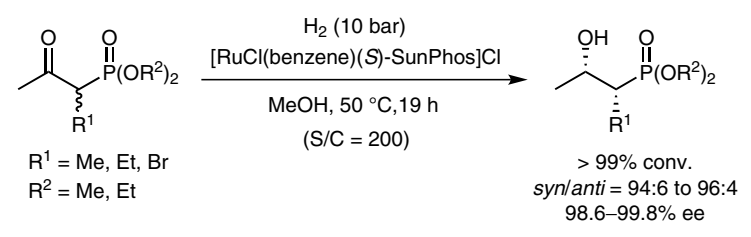

Scheme 14

In 2013, Wang and co-workers depicted a cascade asymmetric hydrogenation/DKR of racemic cyclic $\beta$-keto sulfonamides and $\beta$-keto sulfones derived from $\alpha$-indanone or $\alpha$-tetralone (Scheme 15$).{ }^{31}$ The reaction was performed using $0.4 \mathrm{~mol} \%$ of the cationic complex $[\mathrm{Ru}(\mathrm{OTf})(p-c y-$ mene $)((R, R)$-TsDPEN $)][(R, R)$-CAT3 $]$ in methanol at room temperature under 40 atmospheres of hydrogen pressure to deliver the corresponding cis- $\beta$-hydroxy sulfonamides and $\beta$-hydroxy sulfones in high yields (92-97\%), with excellent enantioselectivities (98\%) and very high diastereoselectivities (cis/trans >99:1).
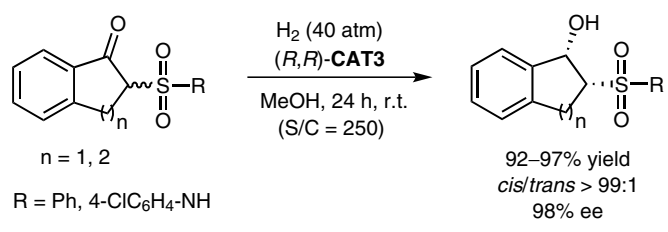

Scheme 15

\section{$2.4 \alpha, \alpha^{\prime}$-Disubstituted Cyclic Ketones}

Zhou, Xie and co-workers developed a strategy for the highly enantioselective ruthenium-catalyzed hydrogenation of racemic $\alpha, \alpha^{\prime}$-disubstituted cyclic ketones through DKR for the synthesis of chiral diols bearing three contiguous stereocenters (Scheme 16). ${ }^{32}$ The reduction of $\alpha$ ethoxycarbonyl-alkyl- $\alpha$-arylcyclic ketones catalyzed by $\left(S_{\mathrm{a}}, R, R\right)$-CAT1 at room temperature under 50 atmospheres of hydrogen pressure delivered the corresponding chiral diols in high yields with excellent cis,cis selectivities (cis,cis/cis,trans >99:1) and enantioselectivities (up to 99.9\% ee), with the ester group being hydrogenated in the process. The size of the cyclic ketone strongly affected the enantioselectivity of the reaction, because only moderate enantioselectivity (75\% ee) was observed with a five-membered ring, whereas six- and seven-membered rings afforded high ee values. The authors showed that both the aryl and ester groups were necessary to achieve high enantioselectivity. In addition, this highly efficient strategy was used for the enantioselective total synthesis of $(+)-\gamma-$ lycorane. 

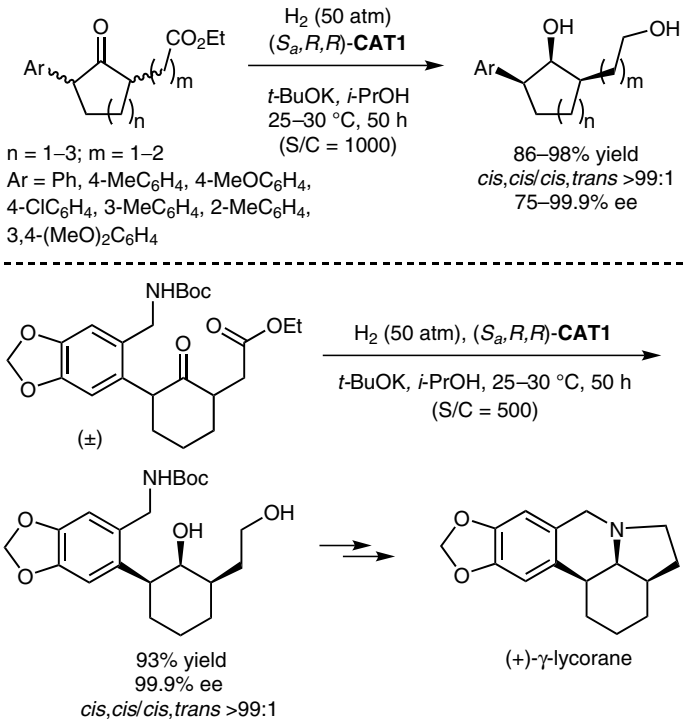

Scheme 16

\section{$2.5 \alpha, \beta$-Disubstituted Cyclic Ketones}

In 2016, Zhou, Xie and co-workers reported the enantioselective total synthesis of (-)-hamigeran B and (-)-4-bromohamigeran $B{ }^{33}$ The key feature of this approach relied on the construction of the chiral cyclopentanol moiety having three contiguous stereocenters by using a highly efficient iridium-catalyzed asymmetric hydrogenation of a racemic ketone via DKR (Scheme 17). Optimization of the reaction conditions revealed that the chiral iridium complex $(R)$ CAT2, bearing a spiropyridine-aminophosphine ligand, was the catalyst of choice for the asymmetric hydrogenation of racemic trans-2-(3-methoxy-2,5-dimethylphenyl)-3(ethoxycarbonyl)cyclopentanone, providing the targeted cyclopentanol in excellent yield (97\%), and with high enantioselectivity (99\% ee) and nearly perfect trans selectivity (trans/cis >99:1).<smiles>CCOC(=O)c1c(OC)cc([N+](=O)[O-])cc1[C@H]1C(=O)CC[C@@H]1OC</smiles>

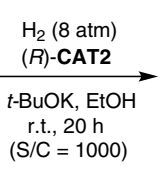
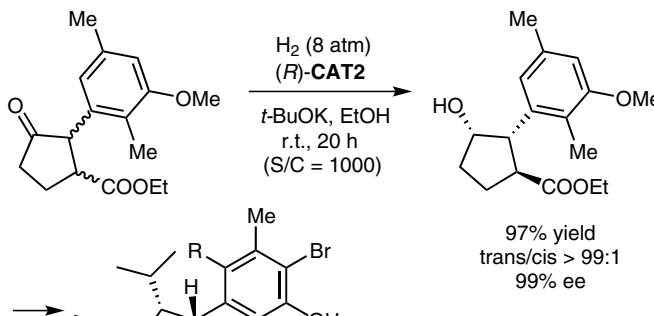

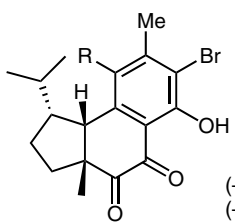

(-)-hamigeran $B(R=H)$ $(-)-4$-bromohamigeran $B(R=B r)$

\subsection{Imine Derivatives}

The reduction of heteroarenes ${ }^{34}$ is still a long-standing challenge in the field of asymmetric reduction and several examples involving DKR can be found in the literature.

In 2012, Zhou and co-workers disclosed the enantioselective hydrogenation of 3,4-disubstituted isoquinolines using $[\operatorname{Ir}(\operatorname{cod}) \mathrm{Cl}]_{2} /(R)$-SYNPHOS as the catalyst and 1-bromo3-chloro-5,5-dimethylhydantoin (BCDMH) as an additive (Scheme 18). ${ }^{35}$ This method afforded chiral 3,4-disubstituted tetrahydroisoquinolines with excellent diastereoselectivities ( $\mathrm{dr}>20: 1$ ) and enantioselectivities up to 96\%. Different control experiments showed that the reaction proceeded via a DKR process involving an imine-enamine tautomerization.

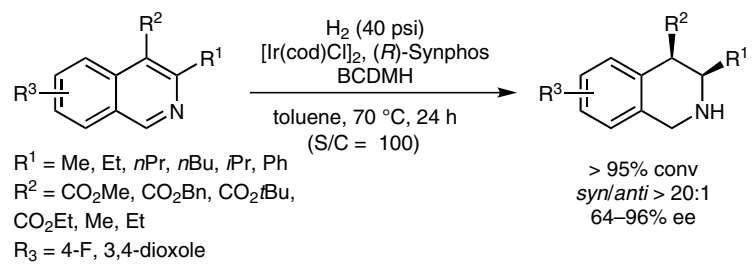

Scheme 18

\section{Asymmetric Transfer Hydrogenation via Dynamic Kinetic Resolution}

Historically, the first example of a catalytic ATH was reported in 1950 by Doering, ${ }^{36}$ who described an asymmetric version of the Meerwein-Ponndorf-Verley (MPV) reduction of ketones catalyzed by rac-aluminum alkoxides in the presence of (S)-2-butanol as a hydrogen donor to give the corresponding chiral alcohols with ee values of $5.9-22 \%$. However, a major breakthrough occurred in 1995, when Noyori, Ikariya and co-workers ${ }^{37}$ designed a conceptually new $\mathrm{Ru}(\mathrm{II})$-arene catalyst bearing $\mathrm{N}$-sulfonylated 1,2-diamines or amino alcohols as chiral ligands for highly efficient ATH of ketones and imines. After this milestone discovery, intense efforts were devoted by the synthetic community for the development of new highly efficient catalyst systems in both academia and industry. ATH is now recognized as one of the most powerful and versatile tools for synthesizing chiral alcohols and amines, because of its operational simplicity, wide substrate scope and high selectivity. Of particular interest is the application of ATHs under DKR conditions that allow highly enantioselective syntheses of chiral alcohols and amines containing two or more stereogenic centers, the first examples of which were reported by the groups of Knochel ${ }^{38}$ and Noyori. ${ }^{39}$ 


\section{1 $\alpha$-Substituted $\beta$-Diketones and Ketones}

In 2011, Zhang and co-workers achieved a practical and highly stereoselective synthesis of 2-aroyl-1-tetralones using $\left[\mathrm{RuCl}_{2}(p \text {-cymene })\right]_{2}$ in combination with $(1 S, 2 S)$-TsDPEN and $\mathrm{HCO}_{2} \mathrm{H} / \mathrm{Et}_{3} \mathrm{~N}$ as the hydrogen source (Scheme 19). ${ }^{40}$ The ATH/DKR reaction using the $(S, S)$-CAT4 complex was applied to a series of diversely substituted 2-aroyl-1tetralones to provide the corresponding alcohols in good yields (up to 85\%) and asymmetric inductions (up to $99 \%$ ee, $>99: 1 \mathrm{dr}$ ). No conversion was observed with ortho-substituted phenyl groups. The authors showed that the steric effect and the rigidity of the fused ring system played a crucial role in the stereochemical outcome of the reaction because significantly lower stereoselectivities (50\% ee, 72:28 $\mathrm{dr}$ ) were obtained with a cyclohexyl diketone derivative.

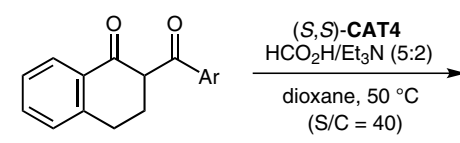

$\mathrm{Ar}=\mathrm{Ph}, 4-\mathrm{MeC}_{6} \mathrm{H}_{4}, 3-\mathrm{MeC}_{6} \mathrm{H}_{4}, 4-\mathrm{MeOC}_{6} \mathrm{H}_{4}$, 3- $\mathrm{MeOC}_{6} \mathrm{H}_{4}, 4-\mathrm{ClC}_{6} \mathrm{H}_{4}, 4-\mathrm{BrC}_{6} \mathrm{H}_{4}, 4-\mathrm{IC}_{6} \mathrm{H}_{4}$, 4- $\mathrm{FC}_{6} \mathrm{H}_{4}$, 2-thienyl, 2-naphthyl

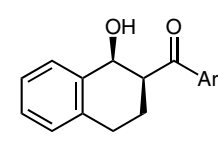

$67-85 \%$ yield syn/anti $=92: 8$ to $>99: 1$ 93-99\% ee
Scheme 19

Omarigliptin is a long-acting DPP-4 inhibitor for the treatment of type 2 diabetes. In 2015, scientists from Merck Research Laboratories developed a synthetic route to this important pharmaceutical drug that was amenable to multikilogram-scale production. One of the reactions featured in this process relied on the use of a Ru-catalyzed DKR reduction of a racemic $N$-Boc- $\alpha$-substituted ketone to provide the desired anti-1,2-amino alcohol bearing two of the three stereogenic centers (Scheme 20). ${ }^{41}$ The best results were obtained with $0.1 \mathrm{~mol} \%$ of the oxo-tethered $[\mathrm{RuCl}((R, R)$-TsDENEB $)]$ complex $[(R, R)$-CAT10] as the catalyst, five equivalents of an azeotropic mixture of formic acid/triethylamine $(5: 2)$ as the hydrogen source, and three equivalents of DABCO. Under these optimized reaction conditions, the key chiral 1,2-amino alcohol intermediate was obtained in 93\% yield with high anti selectivity (anti/syn $=96: 4$ ) and nearly perfect enantioselectivity (99\% ee). In this transformation, it was found that removal of generated $\mathrm{CO}_{2}$ (by purging with $\mathrm{N}_{2}$ ) during the course of the reaction was essential for achieving high catalytic efficiency.

\section{2 $\alpha$-Substituted $\beta$-Keto Esters, Amides and Phos- phonates}

Chiral $\beta$-hydroxy- $\alpha$-amino acid derivatives with an anti configuration are important structural motifs found in a wide variety of biologically active and natural products. Many stereoselective approaches to prepare such building blocks have been reported in the literature, ${ }^{42}$ from which

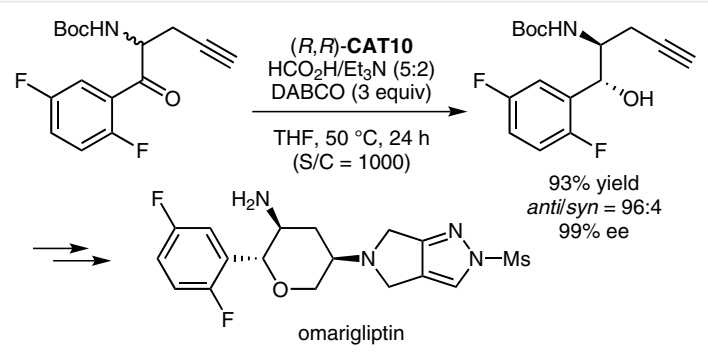

Scheme 20

AH and ATH of $\alpha$-substituted- $\beta$-keto esters, amides and phosphonates are undoubtedly among the most elegant and powerful methods.

In 2011, Liu, Shultz and co-workers from Merck Research Laboratories succeeded in developing a practical and highly stereoselective synthesis of anti aryl $\beta$-hydroxy $\alpha$ amino esters using [ $\mathrm{RuCl}(p$-cymene $\left.)\left((R, R)-\mathrm{C}_{6} \mathrm{~F}_{5} \mathrm{SO}_{2} \mathrm{DPEN}\right)\right]$ complex $\left[(R, R)\right.$-CAT7] and $\mathrm{HCO}_{2} \mathrm{H} / \mathrm{Et}_{3} \mathrm{~N}(5: 2)$ as the hydrogen source, with slow addition of formic acid (42:1 dr, 91\% ee) in dichloromethane for 13-17 hours (Scheme 21). ${ }^{43}$ Careful investigations demonstrated that the combination of an electron-deficient perfluorinated ligand with slow addition of formic acid over five hours was critical to control the stereochemical outcome of the reaction because a significantly lower enantioselectivity (73\% ee) was obtained by using directly the $\mathrm{HCO}_{2} \mathrm{H} / \mathrm{Et}_{3} \mathrm{~N}$ (5:2) azeotropic mixture. These optimized DKR transfer reaction conditions were applied to a series of diversely substituted aryl $\beta$-keto $\alpha$-amino esters bearing both electron-donating and electronwithdrawing substituents on the aromatic ring. A variety of functional groups were tolerated, and the corresponding anti alcohols were obtained in good yields (up to 99\%) and high stereoselectivities (up to >97\% ee, >99:1 dr). The absolute stereochemistry of the desired anti products was assigned unambiguously by chemical derivatization and vibrational circular dichroism spectroscopy.

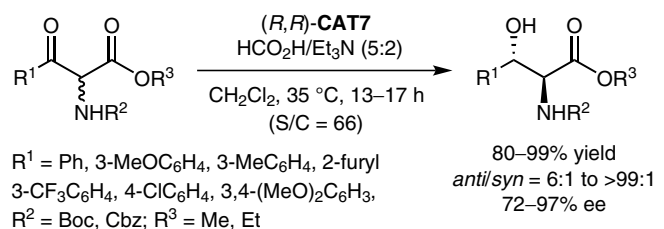

Scheme 21

Somfai and co-workers later described a procedure allowing access to the anti diastereomers using complex $(S, S)$-CAT11 obtained from $\left[\mathrm{RuCl}_{2} \text { (benzene) }\right]_{2}$ and $(S, S)$ BnDPAE $\mathbf{L} 5$ as the ligand, in the presence of $\mathrm{HCO}_{2} \mathrm{H} / \mathrm{Et}_{3} \mathrm{~N}$ as the hydrogen source. The reaction proceeded mainly in excellent diastereoselectivities (anti/syn >99:1) and enantio- 
selectivities (up to 98\% ee) for aryl ketone derivatives in 5-7 days using $10 \mathrm{~mol} \%$ of the ruthenium catalyst in isopropanol (Scheme 22). ${ }^{44}$

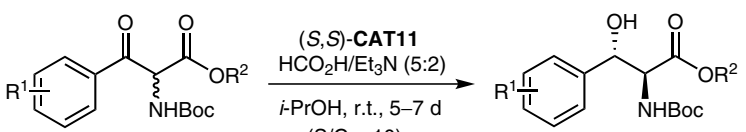

$$
\begin{aligned}
& (\mathrm{S} / \mathrm{C}=10)
\end{aligned}
$$

Scheme 22

The same group disclosed a water- $\mathrm{CH}_{2} \mathrm{Cl}_{2}$ emulsionbased method for the construction of anti- $\beta$-hydroxy $\alpha$ amido esters through ATH/DKR (Scheme 23). ${ }^{45}$ In the presence of the preformed catalyst, $(S, S)$-CAT9, sodium formate as the reducing agent and tetrabutylammonium iodide, the reduction of $\alpha$-amido $\beta$-keto esters proceeded with high diastereo- and enantioselectivities (anti/syn up to 95:5, up to $98 \%$ ee) using a lower catalyst loading $(\mathrm{S} / \mathrm{C}=33)$ than previously, and within shorter reaction times (3-5 days). Moreover, the emulsion conditions provided a significantly broader reaction scope, including aryl-, heteroaryl-, alkenyl-, and even alkyl-substituted $\alpha$-amido $\beta$-keto esters.

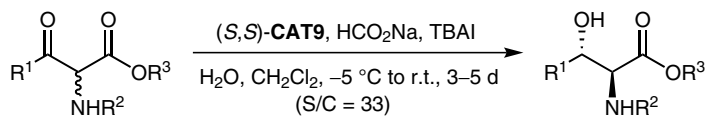

$$
\begin{aligned}
& \mathrm{R}^{1}=\mathrm{Ph}, 2-\mathrm{MeOC}_{6} \mathrm{H}_{4}, 4-\mathrm{FC}_{6} \mathrm{H}_{4}, \quad 79-97 \% \text { yield } \\
& \text { 3- } \mathrm{ClC}_{6} \mathrm{H}_{4} \text {, naphthyl, 2-thienyl, } t \text {-Bu, anti/syn up to }>95: 5 \\
& \text { 1-cyclohexenyl, cyclohexyl, Et } \quad 76-98 \% \text { ee } \\
& \mathrm{R}^{2}=\mathrm{Boc}, \mathrm{Cbz} \\
& \mathrm{R}^{3}=\mathrm{Me}, \mathrm{Et}
\end{aligned}
$$

\section{Scheme 23}

Somfai and co-workers then investigated the same reaction in water, obviating the need for an organic solvent, by employing a neutral surfactant, Tween 20 [polyoxyethylene (20) sorbitan monolaurate] to overcome solubility issues. The procedure gave generally high yields (68-85\%), diastereoselectivities (anti/syn up to 23:1) and enantioselectivities (up to $96 \%$ ee) for a broad range of substrates (Scheme $24) .{ }^{46}$

$$
\begin{aligned}
& \mathrm{R}^{1}=\mathrm{Ph}, 4-\mathrm{FC}_{6} \mathrm{H}_{4}, 4-\mathrm{BrC}_{6} \mathrm{H}_{4}, 3-\mathrm{BrC}_{6} \mathrm{H}_{4}, \\
& \text { 2-MeOC } \mathrm{H}_{4}, 3,4-(\mathrm{MeO})_{2} \mathrm{C}_{6} \mathrm{H}_{3}, 2 \text {-thienyl, } \\
& t \text { - } \mathrm{Bu}, 1-\text { cyclohexenyl, cyclohexyl } \\
& \mathrm{R}^{2}=\text { Boc, } \mathrm{Cbz} ; \mathrm{R}^{3}=\mathrm{Me}, \mathrm{Et}
\end{aligned}
$$

In 2015, our group developed an efficient, flexible and atom-economical synthesis of the four stereoisomers of $(+)$ $(1 R, 2 R)$-thiamphenicol, used for its antibacterial activities against several Gram-positive and Gram-negative microorganisms, through both AH/DKR and ATH/DKR processes using a racemic $\alpha$-amido $\beta$-keto ester (Scheme 25). ${ }^{47}$ The ruthenium-catalyzed asymmetric hydrogenation reaction was carried out under 120 bar of hydrogen pressure at $50{ }^{\circ} \mathrm{C}$ using in-house in situ generated Ru(II)-SYNPHOS ${ }^{23 e}$ as the best catalyst, furnished the corresponding $(2 S, 3 R)$ - and $(2 R, 3 S)$-syn-alcohols in high yields and stereoselectivities (syn/anti $>99 / 1,90 \%$ ee). Alternatively, asymmetric transfer hydrogenation employing the $\left[\mathrm{RuCl}\left(\eta^{6}\right.\right.$-mesitylene $)((S, S)$ TsDPEN)] complex, $(S, S)$ - or $(R, R)$-CAT9 and $\mathrm{HCO}_{2} \mathrm{H} / \mathrm{Et}_{3} \mathrm{~N}$ $(5: 2)$ as the hydrogen source provided, at $50{ }^{\circ} \mathrm{C}$, the anti$(2 R, 3 R)$ - and $(2 S, 3 S)$-isomers, respectively, in $77 \%$ and $95 \%$ isolated yields and in high diastereo- and enantioselectivities (anti/syn $=97: 3$, up to 94\% ee). The complementarity of these reduction methods was demonstrated through the practical access to all the syn and anti stereoisomers of thiamphenicol.

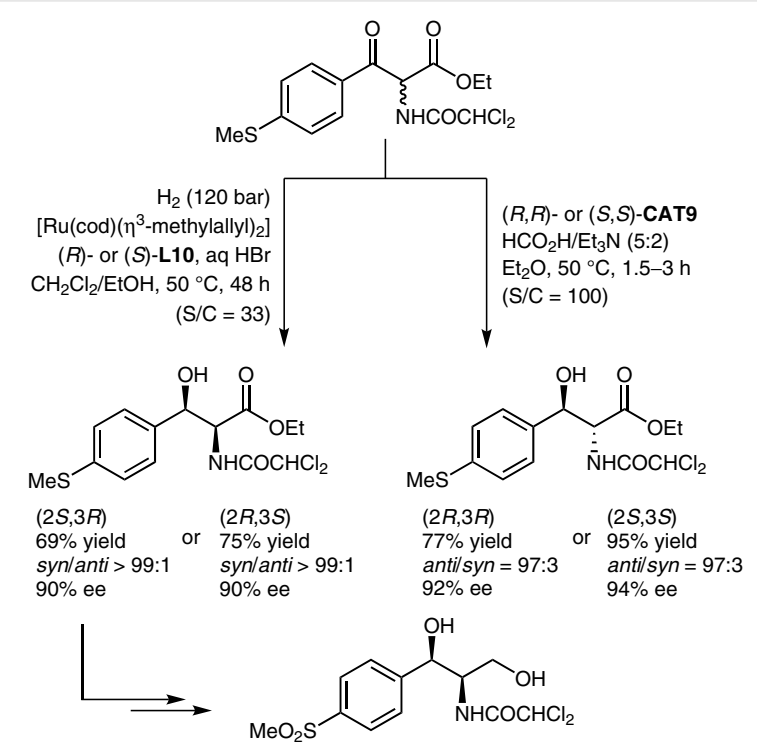

$(+)-(1 R, 2 R)$-thiamphenicol

Scheme 25

We also focused our attention on the first asymmetric transfer hydrogenation of racemic $\alpha$-amino $\beta$-keto ester hydrochlorides (Scheme 26). ${ }^{48}$ The ruthenium-tethered complex $(S, S)$-CAT12, combined with ammonium formate as the hydrogen source, delivered the corresponding anti alcohols in good yields (up to 90\%), diastereo- and enantioselectivities (anti/syn up to $83: 17$, up to $99 \%$ ee) through a DKR process. The operational utility of this ATH was applied to various $\alpha$-amino $\beta$-keto ester hydrochlorides containing both electron-rich and electron-poor aryl groups on the ketone functional group. Interestingly, heteroaromatic com- 
pounds underwent the desired reduction in good yields (up to $79 \%$ ) affording predominantly the syn isomers with excellent enantioselectivities (>98\% ee), albeit with moderate diastereoselectivities (syn/anti up to 68:32).<smiles>[R]C(=O)[C@H](N)C(=O)OC</smiles>

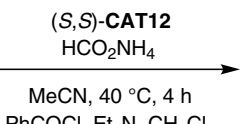

PhCOCl, $\mathrm{Et}_{3} \mathrm{~N}, \mathrm{CH}_{2} \mathrm{Cl}_{2}$ $(\mathrm{S} / \mathrm{C}=50)$

$\mathrm{R}=\mathrm{Ph}, 4-\mathrm{MeC}_{6} \mathrm{H}_{4}, 3-\mathrm{MeC}_{6} \mathrm{H}_{4}$, 4- $\mathrm{MeOC}_{6} \mathrm{H}_{4}, 4-\mathrm{BrC}_{6} \mathrm{H}_{4}, 4-\mathrm{ClC}_{6} \mathrm{H}_{4}$, 4- $\mathrm{FC}_{6} \mathrm{H}_{4}$, 2-thienyl, 2-furyl, 2-naphthyl $86-99 \%$ ee

Scheme 26

Enantiomerically enriched 2-chloro-3-hydroxy esters are key intermediates of several products of medicinal interest. Zhang and co-workers outlined a new stereoselective route to syn-2-chloro-3-hydroxy esters using ATH combined with a DKR process (Scheme 27). ${ }^{49}$ A range of 2chloro-3-oxo esters was smoothly reduced at room temperature using $(S, S)$-CAT4 complex and $\mathrm{HCO}_{2} \mathrm{H} / \mathrm{Et}_{3} \mathrm{~N}$ in dichloromethane. Moderate to good yields (up to 85\%) were observed with good diastereo- and enantioselectivities (syn/anti up to $88: 12,59-98 \%$ ee).<smiles>O=C([O-])C(Cl)C(=O)[O-]</smiles>

$$
\begin{aligned}
& \text { (S,S)-CAT4 }
\end{aligned}
$$

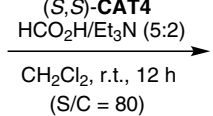

$\mathrm{R}^{1}=\mathrm{Ph}, 4-\mathrm{MeOC}_{6} \mathrm{H}_{4}, 4-\mathrm{FC}_{6} \mathrm{H}_{4}, 4-\mathrm{BrC}_{6} \mathrm{H}_{4}$

2- $-\mathrm{MeC}_{6} \mathrm{H}_{4}, 3-\mathrm{MeC}_{6} \mathrm{H}_{4}, 1$-naphthyl,

2,4- $\mathrm{Cl}_{2} \mathrm{C}_{6} \mathrm{H}_{3}$, 2-thienyl, 2-furyl

$\mathrm{R}^{2}=\mathrm{Me}, \mathrm{Et}$

Scheme 27

In their investigation of the ATH of functionalized acetylenic ketones and diketones using the azeotropic mixture of $\mathrm{HCO}_{2} \mathrm{H} / \mathrm{Et}_{3} \mathrm{~N}$ in combination with complexes $(R, R)$-CAT4 or $(R, R)$-CAT12, Wills and Fang observed an efficient dynamic kinetic resolution with the $\alpha$-methylated derivatives (Scheme 28).$^{50}$ In all cases, the syn product was favored, and the reduction proceeded in high yields (76-99\%) with high diastereo- and enantioselectivities (syn/anti up to $31: 1,98-$ $99 \%$ ee).

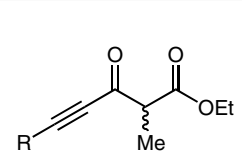

$\mathrm{R}=\mathrm{Ph}, n-\mathrm{Bu},\left(\mathrm{CH}_{2}\right)_{2} \mathrm{OBn}$, $\mathrm{C}(\mathrm{Me})_{2} \mathrm{OBn}$

\section{$(R, R)$-CAT4} or $(R, R)$-CAT12 $\mathrm{HCO}_{2} \mathrm{H} / \mathrm{Et}_{3} \mathrm{~N}(5: 2)$ $(\mathrm{S} / \mathrm{C}=30-200)$

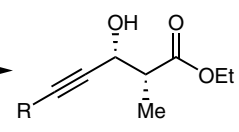

$76-99 \%$ yield syn/anti $=11: 1$ to $31: 1$ $98-99 \%$ ee
Differentiated syn-1,2-diol derivatives are very useful building blocks in organic synthesis and important synthons in natural product synthesis. Our group documented the first direct enantio- and diastereoselective $\mathrm{Rh}(\mathrm{III})-^{51}$ and $\mathrm{Ru}(\mathrm{II})$-promoted asymmetric hydrogen transfer of racemic $\alpha$-alkoxy $\beta$-keto esters in dichloromethane at $30{ }^{\circ} \mathrm{C}$ using $\mathrm{HCO}_{2} \mathrm{H} / \mathrm{Et}_{3} \mathrm{~N}(5: 2) .^{52}$ This novel strategy had a broad scope and accommodated a wide range of electronically diverse $\alpha$-alkoxy $\beta$-keto esters containing aryl-, alkenyl-, alkynyland alkyl-substituted ketones under mild reaction conditions, providing the corresponding $\alpha$-alkoxy $\beta$-hydroxy esters with excellent levels of efficiency and stereocontrol (syn/anti up to 99:1, up to 99\% ee) (Scheme 29). To highlight the value of this new ATH/DKR transformation, a short synthetic route to a key intermediate of AZ-242 Tesaglitazar, which exhibits type II antidiabetic properties, was developed.
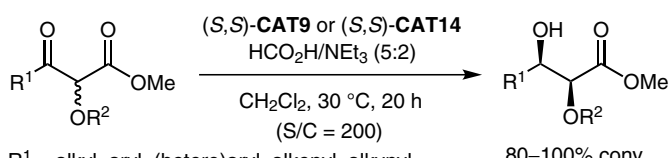

$80-100 \%$ conv

$\mathrm{R}^{1}=$ alkyl, aryl, (hetero)aryl, alkenyl, alkyny $\mathrm{R}^{2}=\mathrm{Me}, \mathrm{Et}, \mathrm{Bn}, \mathrm{PMB}$ syn/anti $=70: 30$ to $99: 1$<smiles></smiles>

Scheme 29

In 2016, Mohar and co-workers achieved the synthesis of several new enantiopure 3-( $\alpha$-aminobenzyl)-benzo- $\gamma$ sultam ligands, which are five-membered cyclic Ts-DPEN analogues. The authors demonstrated that their compounds were excellent ligands in Ru-mediated asymmetric transfer hydrogenation of ketones using triethylammonium formate as a hydride donor (Scheme 30). ${ }^{53}$ In particular, it was found that the use of the in situ generated catalyst $(R, R)$-CAT5, obtained from $\left[\mathrm{RuCl}_{2} \text { (p-cymene) }\right]_{2}$ as the ruthenium source, and $\left(3 R, 1^{\prime} S\right)-\mathbf{L} \mathbf{4}$ as the chiral diamine ligand, in dichloroethane at $40{ }^{\circ} \mathrm{C}$, smoothly converted racemic 2 - or 3methoxycarbonyl-1-indanones into the corresponding chiral alcohols with near-perfect enantioselectivities (up to $>99 \%$ ee) and good to excellent cis diastereoselectivities (cis/trans ranging from 95:5 to 97:3). Similar results were obtained with 2-methoxycarbonyl- $\alpha$-tetralone (99\% ee, cis/trans $=98: 2$ ), whereas no diastereoselectivity was observed for the reduction of 3- and 4-methoxycarbonyl- $\alpha$-tetralones (cis/trans $=50: 50$ ), while maintaining excellent enantioselectivities ( $>99 \%$ ee).

Lee and co-worker showed that ATH/DKR of 2-benzoylmorpholinones proceeded efficiently to give the corresponding $(2 R, 3 S)$ - or $(2 S, 3 R)$-2-(hydroxyphenylmethyl)morpholin-3-ones with an excellent level of diastereo- 

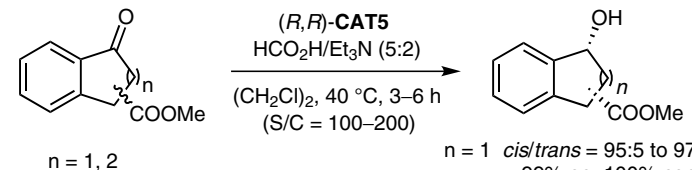

$\mathrm{n}=1 \mathrm{cis} /$ trans $=95: 5$ to $97: 3$ $>99 \%$ ee, $100 \%$ conv. $\mathrm{n}=2$ cis/trans $=50: 50$ to $98: 2$ $>99 \%$ ee, $>99 \%$ conv.

Scheme 30

and enantioselectivity (anti/syn up to 99:1, 95-99\% ee) using $0.5 \mathrm{~mol} \%$ of the ruthenium complex $(R, R)$-CAT9 and $\mathrm{HCO}_{2} \mathrm{H} / \mathrm{Et}_{3} \mathrm{~N}$ (5:2) azeotropic mixture as the hydrogen source (Scheme 31). ${ }^{54}$ In addition, this process was employed to prepare all four stereoisomers of the antidepressant, reboxetine.<smiles>[X]c1ccc(C(=O)C2OCCNC2=O)cc1</smiles>

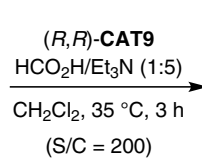<smiles>[Y]=C[GeH3]</smiles><smiles>CCOc1ccccc1OC(c1ccccc1)C1OCC[NH2+]C1=O</smiles>

$(S, S)$-reboxetine

\section{Scheme 31}

In 2015, Kumaraswamy and co-workers used a Ru(II)promoted asymmetric transfer hydrogenation of an $\alpha-$ methylated $\beta$-keto Weinreb amide coupled with a DKR process in their approach to the potent antifungal and cytotoxic agent (+)-crocacin C. This process provided the key syn configuration of the stereotetrad motif (Scheme 32). ${ }^{55}$ Initially, the reaction was performed at $50{ }^{\circ} \mathrm{C}$ in dichloromethane using the 18 -electron complex $[\mathrm{RuCl}(p$-cymene $)((R, R)-$ TsDPEN $)][(R, R)$-CAT4] with a substrate to catalyst ratio of 33 in the presence of $\mathrm{HCO}_{2} \mathrm{H} / \mathrm{Et}_{3} \mathrm{~N}$ (5:2) azeotropic mixture as the hydrogen source. Under these conditions, the enantioenriched acetylenic $\alpha$-methylated $\beta$-hydroxy Weinreb amide was obtained in 60\% yield, $92 \%$ ee, and good diastereoselectivity $($ syn/anti $=92: 8)$. Interestingly, it was found that a better catalytic activity (94\% yield, $98 \%$ ee and syn/anti $=94: 6$ ) could be obtained at a lower catalyst loading $(S / C=100)$ by using the isolated 16-electron Ru-TsDPEN amido complex $(R, R)$-CAT8.

The same group exploited the ATH/DKR reaction for the synthesis of a range of $\delta / \gamma$-alkoxy- $\beta$-hydroxy- $\alpha$-alkyl-substituted Weinreb amides (Scheme 33). ${ }^{56}$ Careful examinations demonstrated that the presence of $\delta$ - or $\gamma$-benzyloxy or alkoxy substituents was essential for the reaction to proceed. The reduction was performed employing $1 \mathrm{~mol} \%$ of

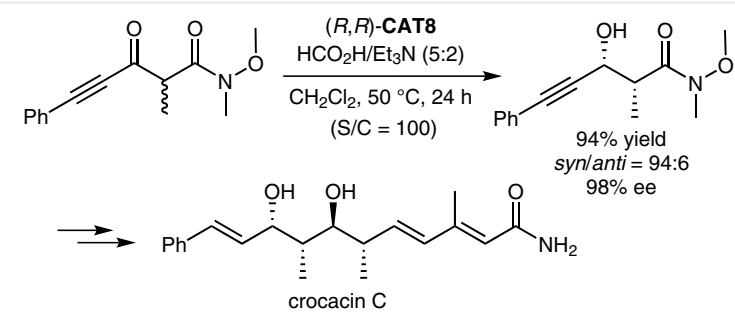

Scheme 32

the preformed complex, [Ru(p-cymene $)((R, R)$-TsDPEN $)]$ $\left[(R, R)\right.$-CAT8], in 2-propanol at $55{ }^{\circ} \mathrm{C}$ with $10 \mathrm{~mol} \%$ of $\mathrm{K}_{2} \mathrm{CO}_{3}$ delivering the expected syn alcohols with high stereoinductions (syn/anti up to 95:5, up to $98 \%$ ee). This key transformation could be scaled to $10 \mathrm{~g}$ and was applied to the preparation of an advanced intermediate of (-)-brevisamide.

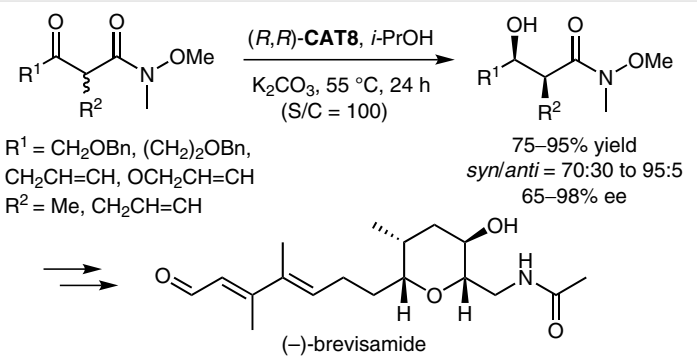

Scheme 33

Lee and co-worker described a general protocol for the ATH of a wide range of racemic 2-substituted $\alpha$-alkoxy $\beta$ keto phosphonates employing a $\mathrm{HCO}_{2} \mathrm{H} / \mathrm{Et}_{3} \mathrm{~N}$ (1:5) azeotropic mixture as the hydrogen source and solvent, along with the well-defined chiral catalyst $(R, R)$-CAT9 (Scheme 34). ${ }^{57}$ The corresponding syn monohydroxy-protected 2aryl-, 2-heteroaryl-, 2-alkyl-, and 2-alkenyl-substituted 1,2dihydroxy phosphonates were produced in high yields (9599\%) and mainly excellent diastereo- and enantioselectivities (syn/anti up to $99: 1$, up to $99 \%$ ee).
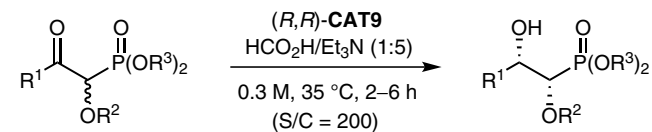

$\mathrm{R}^{1}=$ alkyl, (hetero)aryl, alkeny

$\mathrm{R}^{2}=\mathrm{Me}, \mathrm{Bn}$

$\mathrm{R}^{3}=\mathrm{Me}, \mathrm{Et}$

$$
\begin{gathered}
\text { 95-99\% yield } \\
\text { syn/anti }=60: 40 \text { to } 99: 1 \\
44-99 \% \text { ee }
\end{gathered}
$$

Zhang and co-workers related the DKR of cyclic $\alpha$-tetralone and $\alpha$-indanone derivatives (Scheme 35). The ATH of the corresponding $\beta$-ketosulfonamides proceeded under mild reaction conditions in dioxane at room temperature with high ee (98\%) and dr values (>99:1 dr) using (S,S)-CAT4 
as the catalyst and $\mathrm{HCO}_{2} \mathrm{H} / \mathrm{Et}_{3} \mathrm{~N}(5: 2)$ as the hydrogen donor. ${ }^{58}$

$$
\begin{aligned}
& \text { dioxane, r.t., 24 h } \\
& \mathrm{Ar}=4-\mathrm{ClC}_{6} \mathrm{H}_{4} \quad \mathrm{n}=1,88 \% \text { yield, } \mathrm{dr}>99: 1,98 \% \text { ee } \\
& n=2,91 \% \text { yield, } d r>99: 1,99 \% \text { ee }
\end{aligned}
$$

Scheme 35

The ATH of $N$-benzyl-5-acetyluracil was investigated by Wills and co-workers with the ruthenium catalysts $(R, R)$ CAT12 and $(S, S)$-CAT12 in $\mathrm{HCO}_{2} \mathrm{H} / \mathrm{Et}_{3} \mathrm{~N}(5: 2)$ (Scheme 36). ${ }^{59}$ Interestingly, the use of catalyst $(R, R)$-CAT12 resulted in the formation of the reduced compound in a 4:1 diastereomeric ratio (the relative configuration of the diastereomers was not determined) in $92 \%$ and $33 \%$ ee, respectively, whilst catalyst $(S, S)$-CAT12 gave similar results in terms of stereoselectivity delivering the same major diastereomer. These results suggest that conjugate addition occurred first, resulting in the formation of an enol intermediate, which would tautomerize to give a racemic ketone whose reduction may then proceed via a (dynamic)kinetic resolution.
Scheme 36

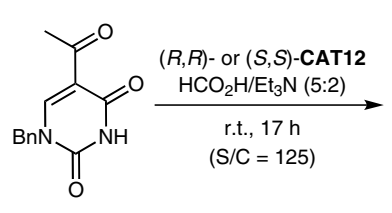

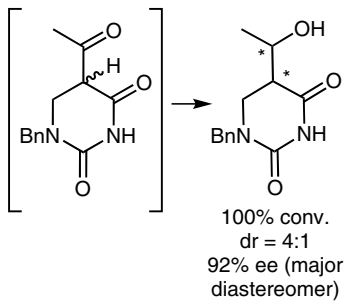

diastereomer)

\section{3 $\beta$-Substituted $\alpha$-Keto Esters and Phosphonates}

The first highly enantioselective ATH/DKR of $\beta$-aryl $\alpha$ keto esters was reported by Johnson and co-workers using a new $\alpha$-naphthyl/diphenylbenzene sulfonamide catalyst, $(S, S)$-CAT6, obtained from $\left[\mathrm{RuCl}_{2}(p \text {-cymene })\right]_{2}$ and the DPEN-based ligand $(S, S)$-L6 (Scheme 37) ${ }^{60}$ Because spontaneous diastereoselective lactonization occurred in the process, this transformation allowed direct access to trisubstituted $\gamma$-butyrolactones in high yields (up to 94\%), establishing three contiguous stereogenic centers with complete diastereocontrol (diastereoselection >20:1) and high enantioselectivities (up to $93 \%$ ee).

The chemoselective ATH/DKR of $\alpha, \delta$-diketo esters was also investigated by these authors using the same catalytic system, (S,S)-CAT6 (Scheme 38). ${ }^{61}$ The selective reduction of the $\alpha$-keto ester in the presence of an aryl ketone allowed the exclusive formation of the corresponding $\delta$-keto $\alpha$-hy-

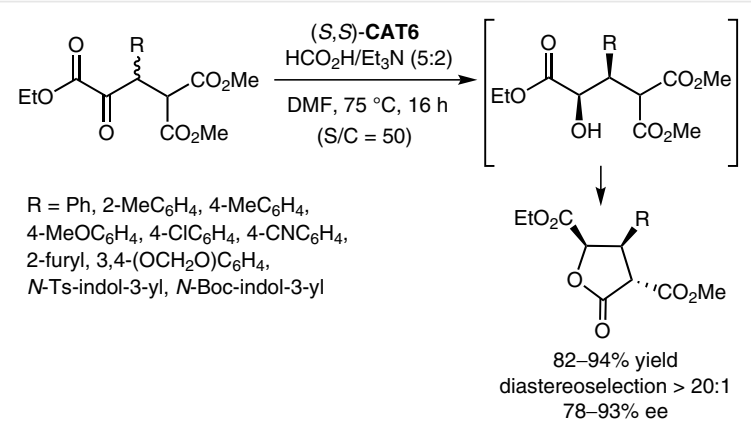

Scheme 37

droxy ester as a single diastereomer. High yields (70-97\%) and enantioselectivities (up to $98 \%$ ee) were obtained for substrates incorporating electron-rich, electron-poor, and heteroaryl substituents at the $\beta$-position. Additionally, the ATH/DKR of $\beta$-chloro $\alpha$-keto esters was developed wherein a remarkable ligand-controlled inversion of the preference for the syn selectivity to provide anti-chlorohydrins was observed. The reaction proceeded with high levels of diastereo- and enantioselectivity for a range of aliphatic and aromatic substrates (anti/syn up to >20:1, up to $99 \%$ ee).

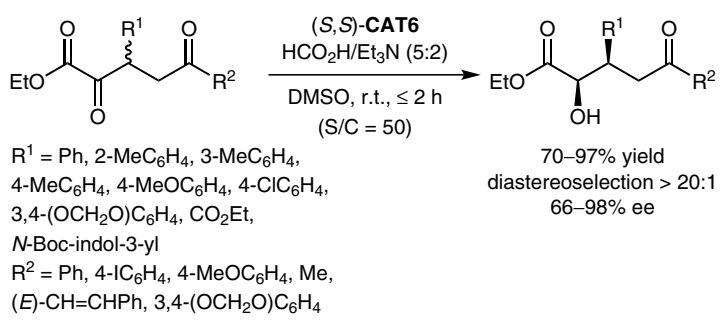

Scheme 38

Johnson and co-workers also developed an approach to enantioenriched anti- $\alpha$-hydroxy- $\beta$-amino acid derivatives by enantioconvergent reduction of racemic $\alpha$-keto esters through $\mathrm{Ru}(\mathrm{II})$-catalyzed ATH. The latter were readily prepared from the corresponding $\alpha$-diazo esters by oxidation with Oxone (Scheme 39). ${ }^{62}$ With the exception of aliphatic $\beta$-substituted substrates, high levels of diastereo- and enantioselectivity were attained with heteroaromatic as well as electron-rich and electron-poor aromatic systems (anti/syn up to $>20: 1$, up to $98 \%$ ee) using $(S, S)$-CAT6 as the catalyst.

Somfai and co-worker disclosed the ATH/DKR of $\beta$-amido $\alpha$-keto esters to give the corresponding anti- $\beta$-amido $\alpha$ hydroxy esters using commercially available or simply prepared chiral ruthenium catalysts (Scheme 40). ${ }^{63}$ By employing $[\mathrm{RuCl}(p$-cymene $)((R, R)-\mathrm{FsDPEN})][(R, R)$-CAT7] as the catalyst and $\mathrm{HCO}_{2} \mathrm{H} / \mathrm{Et}_{3} \mathrm{~N}$ as the reducing agent, the transfer hydrogenation proceeded much faster than on the regioisomeric $\alpha$-amido $\beta$-keto esters and delivered the anti aromat- 


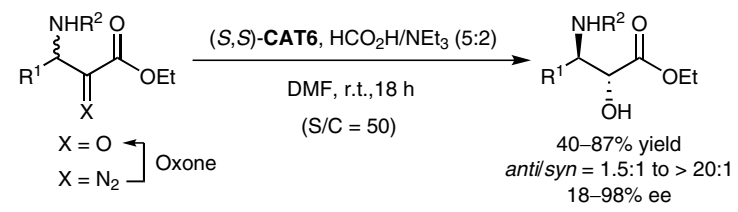

$\mathrm{R}^{1}=\mathrm{Ph}, 2-\mathrm{MeC}_{6} \mathrm{H}_{4}, 4-\mathrm{MeC}_{6} \mathrm{H}_{4}$

3- $\mathrm{MeC}_{6} \mathrm{H}_{4}, 4-\mathrm{MeOC}_{6} \mathrm{H}_{4}, 4-\mathrm{ClC}_{6} \mathrm{H}_{4}$,

4-pinacolBC $\mathrm{B}_{6} \mathrm{H}_{4}, 3,4-\left(\mathrm{OCH}_{2} \mathrm{O}\right) \mathrm{C}_{6} \mathrm{H}_{4}$, naphthyl,

2-thienyl, 2-furyl, $\mathrm{N}$-Boc-indol-3-yl, $\mathrm{PhCH}_{2} \mathrm{CH}_{2}$

$\mathrm{R}^{2}=\mathrm{Boc}, \mathrm{Cbz}$

\section{Scheme 39}

ic and heteroaromatic compounds as the only detectable diastereomers in good yields and usually with high enantioselectivities (up to $98 \%$ ee).

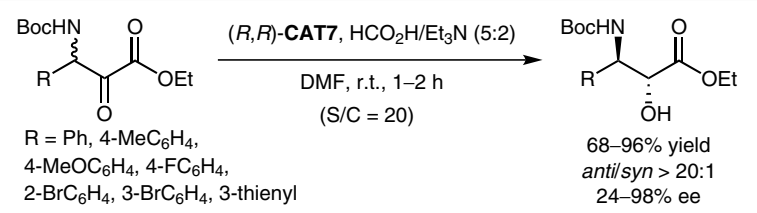

\section{Scheme 40}

Johnson and Corbett related the first highly selective dynamic kinetic resolution of acyl phosphonates through ruthenium-mediated ATH with an unexpected reversal in facial selectivity as compared to the analogous reduction of $\alpha$-keto esters (Scheme 41). ${ }^{64}$ The highest diastereoselectivities ( $\mathrm{dr}$ up to $>20: 1$ ) were observed using $\left[\mathrm{RuCl}_{2}(p-c y-\right.$ mene) $]_{2}$ associated with the bulky $\alpha$-naphthyl ethylenediamine-derived ligand $(S, S)$-L6 to generate the corresponding complex $(S, S)$-CAT6. A variety of electron-donating and electron-withdrawing groups were tolerated, including heteroaromatic substituents as well as linear and cyclic aliphatic substituents, and the ATH of these substrates provided the reduced products in high yields and enantioselectivities (up to $99 \%$ ee).
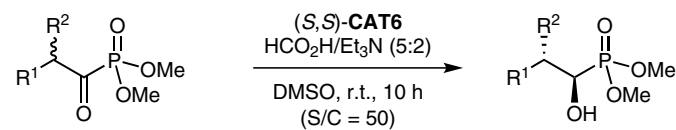

$\mathrm{R}^{1}=\mathrm{Et}$, allyl, propargyl, Bn, cyclopropyl

$\mathrm{R}^{2}=\mathrm{Ph}, 4-\mathrm{MeC}_{6} \mathrm{H}_{4}, 4-\mathrm{MeOC}_{6} \mathrm{H}_{4}$,

2- $\mathrm{MeOC}_{6} \mathrm{H}_{4}, 4-\mathrm{BrC}_{6} \mathrm{H}_{4}, 4-\mathrm{NO}_{2} \mathrm{C}_{6} \mathrm{H}_{4}$,

$84-94 \%$ yield

$\mathrm{dr}=5: 1$ to $>20: 1$

$97-99 \%$ ee

Scheme 41

\section{4 $\beta$-Substituted $\boldsymbol{\gamma}$-Keto Esters}

In 2014, a short enantioselective synthesis of the synthetic strigolactone (+)-GR24 was described by McErlean and co-workers (Scheme 42$).{ }^{65}$ One of the key steps in this

approach relied on the DKR of a racemic indanone via asymmetric transfer hydrogenation. The reaction was performed in the presence of a $\mathrm{HCO}_{2} \mathrm{H} / i-\mathrm{Pr}_{2} \mathrm{NEt}$ mixture as the hydrogen source, using $4 \mathrm{~mol} \%$ of Noyori's ( $S, S)$-CAT4 as the catalyst to afford exclusively, after acid-mediated epimerization, the desired chiral lactone intermediate in $80 \%$ yield and $92 \%$ ee. This could be improved to $>99 \%$ ee after a single recrystallization. Interestingly, the use of the $(R, R)$ CAT4 enantiomer as the catalyst delivered the corresponding (-)-GR24 strigolactone with similar efficiency.

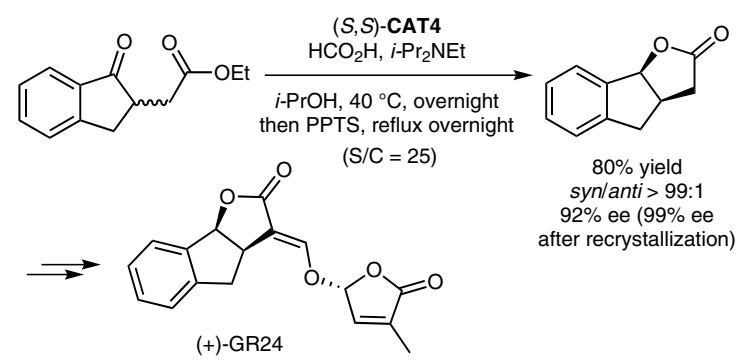

Scheme 42

\section{$3.5 \quad \beta$-Alkoxy Ketones}

Phthalide frameworks are structural subunits that can be found in a large number of natural products, many of which demonstrate a wide range of biological activity. In 2015, Chen and co-workers showed that by using $0.2 \mathrm{~mol} \%$ of Noyori's [RuCl(mesitylene $)((S, S)-T s D P E N)]$ complex $\left[(S, S)\right.$-CAT9] as the catalyst and $\mathrm{HCO}_{2} \mathrm{H} / \mathrm{Et}_{3} \mathrm{~N}$ as the hydrogen source in dichloromethane at $40{ }^{\circ} \mathrm{C}$, a variety of $3-(2-$ oxo-arylethyl)isobenzofuran-1(3H)-ones could be efficiently reduced to the corresponding optically active phthalide derivatives bearing 1,3-diastereocenters (Scheme 43). ${ }^{66}$ The yield (90-97\%) and enantioselectivity (up to 99\% ee) of the reaction seemed to be insensitive to both the position and the electronic and steric properties of the substituents on the aryl ring. However, only poor to good diastereomeric ratios ranging from 69:31 to 90:10 were achieved under these conditions.<smiles>[R]C(=O)C[C@H]1OC(=O)c2ccccc21</smiles>

$\mathrm{R}=\mathrm{Ph}, 4-\mathrm{FC}_{6} \mathrm{H}_{4}, 4-\mathrm{ClC}_{6} \mathrm{H}_{4}, 4-\mathrm{CNC}_{6} \mathrm{H}_{4}$, 4- $\mathrm{MeC}_{6} \mathrm{H}_{4}, 4-i-\mathrm{PrC}_{6} \mathrm{H}_{4}, 4-\mathrm{MeOC}_{6} \mathrm{H}_{4}$, $3-\mathrm{FC}_{6} \mathrm{H}_{4}, 3-\mathrm{ClC}_{6} \mathrm{H}_{4}, 3-\mathrm{BrC}_{6} \mathrm{H}_{4}$,

3- $\mathrm{MeOC}_{6} \mathrm{H}_{4}, 2-\mathrm{MeOC}_{6} \mathrm{H}_{4}, 2,4-\mathrm{Me}_{2} \mathrm{C}_{6} \mathrm{H}_{4}$ 2-naphthyl, 2-thienyl, 2-furyl
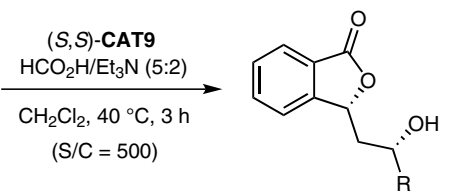

90-97\% yield syn/anti $=69: 31$ to $90: 10$ $99 \%$ ee
Scheme 43 


\subsection{Imine Derivatives ${ }^{4 m, 67}$}

The first report on the ATH of imines associated with a DKR process was published in 2005 by Fernández and coworkers. ${ }^{68}$ The reduction of 2-substituted bicyclic and monocyclic ketimines using a $\mathrm{HCO}_{2} \mathrm{H} / \mathrm{Et}_{3} \mathrm{~N}$ azeotropic mixture as the hydrogen source and $[\mathrm{RuCl}(p$-cymene $)(R, R)$-TsDPEN] [(R,R)-CAT4] or [IrClCp*((S,S)-TsDPEN)] [(S,S)-CAT13] as the catalyst afforded the corresponding cycloalkylamines with excellent cis selectivities in all cases (Scheme 44). For the bicyclic substrates, the Ru(II) catalyst $(R, R)$-CAT4 afforded moderate to good yields with enantioselectivities up to $97 \%$, after extended reaction times ( 5 to 6 days, Scheme 44 , a). On the other hand, the less bulky monocyclic substrates gave better results in Ir(III)-mediated reactions, with high cis selectivities and enantioselectivities of up to $72 \%$ being observed with (S,S)-CAT13 (Scheme 44, b). Moreover, to overcome the difficulties encountered in some imine syntheses, the authors also described a one-pot procedure starting from the corresponding ketones, with similar overall yields and selectivities. They showed that imines reacted faster than ketones under ATH conditions, as previously reported by the group of Noyori. ${ }^{69}$ (a)

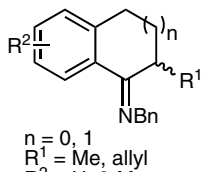
$\mathrm{R}^{1}=\mathrm{Me}$, allyl
$\mathrm{R}^{2}=\mathrm{H}, 3-\mathrm{Me}$

(b)

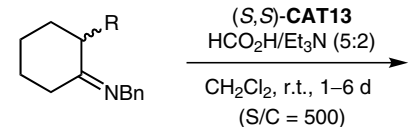
$\mathrm{R}=\mathrm{Ph}$, allyl, $\left(\mathrm{CH}_{2}\right)_{2} \mathrm{CN}$

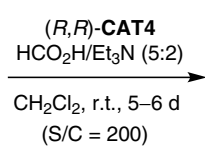
$(\mathrm{S} / \mathrm{C}=200)$ $(\mathrm{S} / \mathrm{C}=500)$

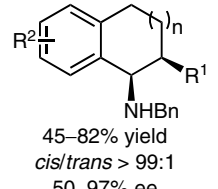

$50-97 \%$ ee

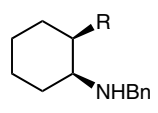

$55-75 \%$ yield cis/trans $=93: 7$ to $>99: 1$ $50-72 \%$ ee
Scheme 44

In 2010, Lee and co-workers published the first example of the ATH of racemic 4,5-disubstituted cyclic sulfamidates via DKR, using [RhClCp* $((R, R)-(\operatorname{TsDPEN}))][(R, R)$-CAT14] as the catalyst and $\mathrm{HCO}_{2} \mathrm{H} / \mathrm{Et}_{3} \mathrm{~N}$ azeotropic mixture as the hydrogen source (Scheme 45$).^{70}$ The reduced compound was obtained in excellent yield, perfect cis diastereoselectivity and an enantioselectivity of $75 \%$.
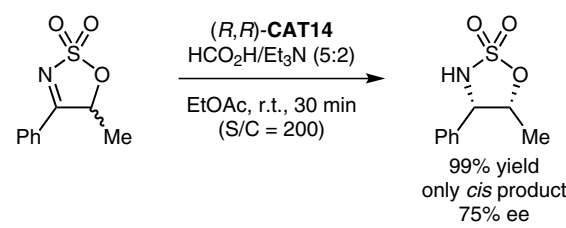

Scheme 45
The same authors found that replacing the methyl substituent at the 5-position by an aryl group resulted in a considerable increase in enantioselectivity, from $75 \%$ to $99 \%$ (Scheme 46$).{ }^{71}$ This might be explained by a more rapid racemization at the stereocenter owing to enhancement of the lability of the related hydrogen. A broad scope of aryl substituents showed excellent yields and high stereoselectivities (cis/trans $>20: 1$, up to $99 \%$ ee). Notably, substrates bearing electron-withdrawing groups at the ortho-position displayed low enantioselectivities (22\%). Surprisingly, when a cyclic sulfamidate imine possessing an electron-donating group at the para-position was subjected to the optimized ATH reaction conditions, only the starting material was recovered.

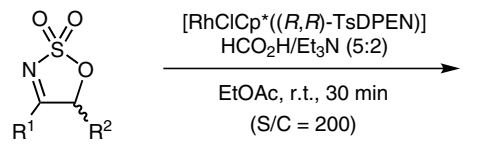

$\mathrm{R}^{1}=\mathrm{Ph}, 2-\mathrm{ClC}_{6} \mathrm{H}_{4}, 3-\mathrm{ClC}_{6} \mathrm{H}_{4}, 4-\mathrm{ClC}_{6} \mathrm{H}_{4}$,

$4-\mathrm{FC}_{6} \mathrm{H}_{4}, 4-\mathrm{CF}_{3} \mathrm{C}_{6} \mathrm{H}_{4}, 3-\mathrm{MeOC}_{6} \mathrm{H}_{4}, 4-\mathrm{MeOC}_{6} \mathrm{H}_{4}$,

$3-\mathrm{MeC}_{6} \mathrm{H}_{4}, 4-\mathrm{MeC}_{6} \mathrm{H}_{4}$

$\mathrm{R}^{2}=\mathrm{Ph}, 2-\mathrm{ClC}_{6} \mathrm{H}_{4}, 3-\mathrm{ClC}_{6} \mathrm{H}_{4}, 4-\mathrm{ClC}_{6} \mathrm{H}_{4}$,

4- $\mathrm{FC}_{6} \mathrm{H}_{4}, 4-\mathrm{CF}_{3} \mathrm{C}_{6} \mathrm{H}_{4}, 3-\mathrm{MeOC}_{6} \mathrm{H}_{4}, 4-\mathrm{MeOC}_{6} \mathrm{H}_{4}$,

$3-\mathrm{MeC}_{6} \mathrm{H}_{4}, 4-\mathrm{MeC}_{6} \mathrm{H}_{4}$

Scheme 46

The same group reported the use of this method for a straightforward route to both enantiomers of norpseudoephedrine, an alkaloid possessing psychostimulant activities and showing numerous uses as a ligand in asymmetric synthesis. ${ }^{72}$ Commercially available 1-hydroxy-1-phenylpropan-2-one was easily converted into the cyclic sulfamidate imine, which was subjected to the ATH reaction using $0.3 \mathrm{~mol} \%$ of the Rh catalyst $(R, R)$-CAT14 in combination with $\mathrm{HCO}_{2} \mathrm{H} / \mathrm{Et}_{3} \mathrm{~N}$ as the hydrogen source to afford only the cis product with excellent yield (93\%) and enantioselectivity (96\%, improved to $99 \%$ after recrystallization). The product was then easily transformed into the desired $(1 S, 2 S)$ norpseudoephedrine after four steps including the inversion of configuration at C-1 without loss of optical purity (Scheme 47).

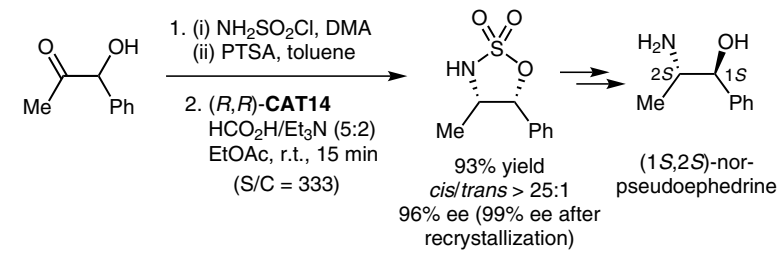

Scheme 47

To extend the scope of the reaction and to demonstrate the utility of this transformation, Lee and co-workers applied the Rh-catalyzed ATH/DKR procedure to substrates bearing a carboxylate group at the acidic stereogenic posi- 
tion. Several substituted sulfamidates have been reduced under these conditions with excellent yields (54-99\%) and stereoselectivity (only cis product, up to 99\% ee) (Scheme 48). ${ }^{73}$ It should be pointed out that several substrates bearing alkyl substituents have also been reduced with moderate to high levels of stereoselectivity. The authors observed that changing the $\mathrm{HCO}_{2} \mathrm{H} / \mathrm{Et}_{3} \mathrm{~N}$ ratio from $5: 2$ to $1: 1$ had a significant positive effect on both the reactivity and the stereochemical outcome of the reaction. ${ }^{74}$ Moreover, using the aforementioned ATH/DKR process as a key step, convenient and highly stereoselective syntheses of (-)-epi-cytoxazone and of the taxotere side-chain were achieved.
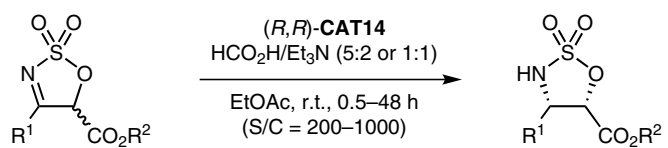

$\mathrm{R}^{1}=\mathrm{C}_{6} \mathrm{H}_{5}, 2-\mathrm{MeC}_{6} \mathrm{H}_{4}, 3-\mathrm{MeC}_{6} \mathrm{H}_{4}$, 4- $\mathrm{MeC}_{6} \mathrm{H}_{4}, 3-\mathrm{ClC}_{6} \mathrm{H}_{4}, 4-\mathrm{ClC}_{6} \mathrm{H}_{4}, 4-\mathrm{MeOC}_{6} \mathrm{H}_{4}$ $4-\mathrm{FC}_{6} \mathrm{H}_{4}, 4-\mathrm{CF}_{3} \mathrm{C}_{6} \mathrm{H}_{4}, 4-\mathrm{CNC}_{6} \mathrm{H}_{4}$, 4- $\mathrm{MeO}_{2} \mathrm{CC}_{6} \mathrm{H}_{4}$, 2-naphthyl, 2-furanyl, 2-thiophenyl, $n$ - $\mathrm{Pr}, \mathrm{Ph}\left(\mathrm{CH}_{2}\right)_{2}$, cyclohexyl $\mathrm{R}^{2}=\mathrm{Me}, i-\mathrm{Pr}, \mathrm{Bn}, t-\mathrm{Bu}$
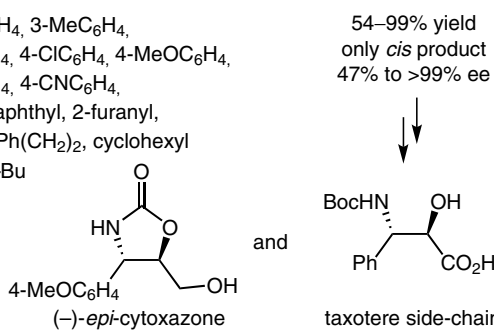

taxotere side-chain

\section{Scheme 48}

Finally, reduction by ATH/DKR of cyclic sulfamidates bearing a phosphonate group was reported in 2015 by Lee and co-workers using the chiral $\left[\operatorname{RhClCp}^{*}((R, R)-\mathrm{TsDPEN})\right]$ $\left[(R, R)\right.$-CAT14] catalyst and $\mathrm{HCO}_{2} \mathrm{H} / \mathrm{Et}_{3} \mathrm{~N}$ as the hydrogen source (Scheme 49). ${ }^{75}$ Compounds with electron-withdrawing and electron-donating groups as well as heteroaryl and alkyl-bearing substrates have been reduced with high yields (up to 99\%) and stereoselectivities (only the cis product was obtained, up to $>99 \%$ ee).
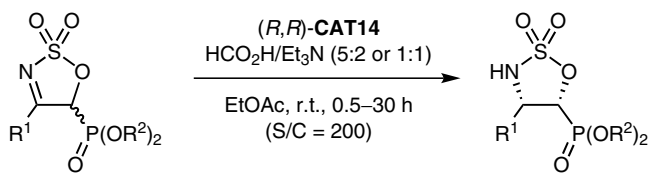

$\mathrm{R}^{1}=\mathrm{C}_{6} \mathrm{H}_{5}, 2-\mathrm{MeC}_{6} \mathrm{H}_{4}, 4-\mathrm{MeC}_{6} \mathrm{H}_{4}$

$3-\mathrm{ClC}_{6} \mathrm{H}_{4}, 4-\mathrm{ClC}_{6} \mathrm{H}_{4}, 4-\mathrm{MeOC}_{6} \mathrm{H}_{4}$

$4-\mathrm{FC}_{6} \mathrm{H}_{4}, 2-\mathrm{FC}_{6} \mathrm{H}_{4}, 4-\mathrm{CNC}_{6} \mathrm{H}_{4}$

4- $\mathrm{MeO}_{2} \mathrm{CC}_{6} \mathrm{H}_{4}$, 2-naphthyl, 2-furanyl,

2-thiophenyl, $\mathrm{Ph}\left(\mathrm{CH}_{2}\right)_{2}$, cyclohexyl, $i$-Pr, $t$-Bu, $i$-Bu

$\mathrm{R}^{2}=\mathrm{Me}, \mathrm{Et}$

Scheme 49

\section{Conclusion}

Asymmetric reduction of ketone and imine derivatives to access chiral alcohols and amines is a major synthetic organic transformation. In this context, asymmetric hydroge- nation and transfer hydrogenation reactions based on dynamic kinetic resolution processes using organometallic catalysts enable the transformation of inexpensive, prochiral starting materials into high-value building blocks. These methods allow efficient access to pharmaceutical agents and natural products via a simple one-step procedure, with high diastereo- and enantiocontrol of the target structures. This review demonstrates the utility of such homogeneous catalytic processes, which can be used for the production of high-profile medicinal targets in operationally simple and broadly general protocols.

\section{Acknowledgment}

The contributions of all current and past group members are gratefully acknowledged. This work was supported by the CNRS (Centre National de la Recherche Scientifique) and the MENESR (Ministère de l'Education nationale, de l'Enseignement supérieur et de la Recherche). P.-G.E. is grateful to the Agence Nationale de la Recherche (ANR11-BS07-017-02) for a grant (2011-2014). We also gratefully acknowledge financial support from our industrial partners.

\section{References}

(1) (a) Noyori, R. Angew. Chem. Int. Ed. 2013, 52, 79. (b) Fürstner, A. Angew. Chem. Int. Ed. 2014, 53, 8587.

(2) (a) Handbook of Homogeneous Hydrogenation; Vol. 1; de Vries, J. G.; Elsevier, C. J., Eds.; Wiley-VCH: Weinheim, 2007. (b) Modern Reduction Methods; Andersson, P. G.; Munslow, I. J., Eds.; WileyVCH: Weinheim, 2008.

(3) For comprehensive reviews and chapters on asymmetric hydrogenation (AH), see: (a) Knowles, W. S. Angew. Chem. Int. Ed. 2002, 41, 1998. (b) Noyori, R. Angew. Chem. Int. Ed. 2002, 41, 2008. (c) Genêt, J.-P. Acc. Chem. Res. 2003, 36, 908. (d) Blaser, H.U.; Malan, C.; Pugin, B.; Spindler, F.; Steiner, H.; Studer, M. Adv. Synth. Catal. 2003, 345, 103. (e) Zhou, Y.-G. Acc. Chem. Res. 2007, 40, 1357. (f) Shang, G.; Li, W.; Zhang, X. In Catalytic Asymmetric Synthesis; Ojima, I., Ed.; John Wiley \& Sons: New York, 2010, 3rd ed. 343. (g) Xie, J. H.; Zhu, S. F.; Zhou, Q. L. Chem. Rev. 2011, 111, 1713. (h) Gopalaiah, K.; Kagan, H. B. Chem. Rev. 2011, 111, 4599. (i) Wang, D.-S.; Chen, Q.-A.; Lu, S.-M.; Zhou, Y.-G. Chem. Rev. 2012, 112, 2557. (j) Chen, Q.-A.; Ye, Z.-S.; Duan, Y.; Zhou, Y.-G. Chem. Soc. Rev. 2013, 42, 497. (k) Li, Y.-Y.; Yu, S.-L.; Shen, W.-Y.; Gao, J.-X. Acc. Chem. Res. 2015, 48, 2587. (l) Xie, J.-H.; Bao, D.-H.; Zhou, Q.-L. Synthesis 2015, 47, 460.

(4) For comprehensive reviews and chapters on asymmetric transfer hydrogenation (ATH), see: (a) Zassinovich, G.; Mestroni, G.; Gladiali, S. Chem. Rev. 1992, 92, 1051. (b) de Graauw, C. F.; Peters, J. A.; van Bekkum, H.; Huskens, J. Synthesis 1994, 1007. (c) Noyori, R.; Hashiguchi, S. Acc. Chem. Res. 1997, 30, 97. (d) Palmer, M. J.; Wills, M. Tetrahedron: Asymmetry 1999, 10, 2045. (e) Pàmies, O.; Backvall, J.-E. Chem. Eur. J. 2001, 7, 5052. (f) Everaere, K.; Mortreux, A.; Carpentier, J.-F. Adv. Synth. Catal. 2003, 345, 67. (g) Gladiali, S.; Alberico, E. Chem. Soc. Rev. 2006, 35, 226. (h) Joseph, S. M.; Samec, J. S.; Bäckvall, J.-E.; Andersson, P. G.; Brandt, P. Chem. Soc. Rev. 2006, 35, 237. (i) Ikariya, T.; Blacker, A. J. Acc. Chem. Res. 2007, 40, 1300. (j) Blacker, A. J. In Handbook of Homogeneous Hydrogenation; de Vries, J. G.; Elsevier, C. J., Eds.; Wiley-VCH: Weinheim, 2007, 1215. (k) Wang, C.; Wu, X.; Xiao, J. Chem. Asian J. 2008, 3, 1750. 
(l) Ikariya, T. Bull. Chem. Soc. Jpn. 2011, 84, 1. (m) Bartoszewicz, A.; Ahlsten, N.; Martín-Matute, B. Chem. Eur. J. 2013, 19, 7274. (n) Slagbrand, H.; Lundberg, H.; Adolfsson, H. Chem. Eur. J. 2014, 20, 16102. (o) Štefane, B.; Požgan, F. Catal. Rev. 2014, 56, 82. (p) Wang, D.; Astruc, D. Chem. Rev. 2015, 115, 6621. (q) Foubelo, F.; Nájera, C.; Yus, M. Tetrahedron: Asymmetry 2015, 26, 769.

(5) For the use of AH in industrial processes, see: (a) Ager, D. J.; de Vries, A. H. M.; de Vries, J. G. Chem. Soc. Rev. 2012, 41, 3340. For the use of ATH in industrial processes, see: (b) Cotarca, L.; Verzini, M.; Volpicelli, R. Chim. Oggi 2014, 32, 36. For the complementarity between AH and ATH, see: (c) Verzijl, G. K. M.; de Vries, A. H. M.; de Vries, J. G.; Kapitan, P.; Dax, T.; Helms, M.; Nazir, Z.; Skranc, W.; Imboden, C.; Stichler, J.; Ward, R. A.; Abele, S.; Lefort, L. Org. Process Res. Dev. 2013, 17, 1531.

(6) (a) Noyori, R.; Tokunaga, M.; Kitamura, M. Bull. Chem. Soc. Jpn. 1995, 68, 36. (b) Caddick, S.; Jenkins, K. Chem. Soc. Rev. 1996, 25 , 447. (c) Ward, R. S. Tetrahedron: Asymmetry 1995, 6, 1475. (d) Sturmer, R. Angew. Chem. Int. Ed. 1997, 36, 1173. (e) El Gihani, M. T.; Williams, J. M. J. Curr. Opin. Chem. Biol. 1999, 3, 11. (f) Ratovelomanana-Vidal, V.; Genêt, J.-P. Can. J. Chem. 2000, 851, 846. (g) Huerta, F. F.; Minidis, A. B. E.; Bäckvall, J. Chem. Soc. Rev. 2001, 30, 321. (h) Faber, K. Chem. Eur. J. 2001, 7, 5005. (i) Pàmies, O.; Bäckvall, J.-E. Chem. Rev. 2003, 103, 3247. (j) Pellissier, H. Tetrahedron 2003, 59, 8291. (k) Turner, N. J. Curr. Opin. Chem. Biol. 2004, 8, 114. (l) Vedejs, E.; Jure, M. Angew. Chem. Int. Ed. 2005, 44, 3974. (m) Martín-Matute, B.; Bäckvall, J.-E. Curr. Opin. Chem. Biol. 2007, 11, 226. (n) Pellissier, H. Tetrahedron 2008, 64, 1563. (o) Pellissier, H. Tetrahedron 2011, 67, 3769.

(7) Tai, A.; Watanabe, H.; Harada, T. Bull. Chem. Soc. Jpn. 1979, 52, 1468.

(8) Noyori, R.; Ikeda, T.; Ohkuma, T.; Widhalm, M.; Kitamura, M.; Takaya, H.; Akutagawa, S.; Sayo, N.; Saito, T. J. Am. Chem. Soc. 1989, 111, 9134.

(9) Jugé, S.; Genêt, J.-P.; Mallard, S. French Patent 89/11 159, 1989; WO 91/02588, 1991.

(10) Kitamura, M.; Tokunaga, M.; Noyori, R. J. Am. Chem. Soc. 1993, $115,144$.

(11) Kitamura, M.; Tokunaga, M.; Noyori, R. Tetrahedron 1993, 49, 1853.

(12) Xie, J.-H.; Zhou, Q.-L. Aldrichimica Acta 2015, 48, 33.

(13) Pellissier, H. Adv. Synth. Catal. 2011, 353, 659.

(14) (a) Applegate, G. A.; Berkowitz, D. B. Adv. Synth. Catal. 2015, 357, 1619. (b) Rachwalski, M.; Vermue, N.; Rutjes, F. P. J. T. Chem. Soc. Rev. 2013, 42, 9268.

(15) Akashi, M.; Arai, N.; Inoue, T.; Ohkuma, T. Adv. Synth. Catal. 2011, 353, 1955.

(16) Chung, J. Y. L.; Steinhuebel, D.; Krska, S.-W.; Hartner, F.-W.; Cai, C.; Rosen, J.; Mancheno, D.-E.; Pei, T.; DiMichele, L.; Ball, R.-G.; Chen, C.-Y.; Tan, L.; Alorati, A.-D.; Brewer, S.-E.; Scott, J.-P. Org. Process Res. Dev. 2012, 16, 1832.

(17) (a) Cheng, L.-J.; Xie, J.-H.; Chen, Y.; Wang, L.-X.; Zhou, Q.-L. Adv. Synth. Catal. 2012, 354, 1105. (b) Li, G.; Xie, J.-H.; Hou, J.; Zhu, S.-F.; Zhou, Q.-L. Adv. Synth. Catal. 2013, 355, 1597. (c) Cheng, L.-J.; Xie, J.-H.; Chen, Y.; Wang, L.-X.; Zhou, Q.-L. Org. Lett. 2013, $15,764$.

(18) Cheng, J.-Q.; Xie, J.-H.; Bao, D.-H.; Zhou, Q.-L. Org. Lett. 2012, 14, 2714.

(19) Chen, C.-Y.; Weisel, M. Synlett 2013, 24, 189.

(20) (a) Phansavath, P.; Duprat de Paule, S.; Ratovelomanana-Vidal, V.; Genêt, J.-P. Eur. J. Org. Chem. 2000, 3903. (b) Lavergne, D.; Mordant, C.; Ratovelomanana-Vidal, V.; Genêt, J.-P. Org. Lett. 2001, 3, 1909. (c) Mordant, C.; Cano de Andrade, M. C.; Touati,
R.; Ben Hassine, B.; Ratovelomanana-Vidal, V.; Genêt, J.-P. Synthesis 2003, $2405 . \quad$ (d) Mordant, C.; Dunkelmann, P.; Ratovelomanana-Vidal, V.; Genêt, J.-P. Chem. Commun. 2004, 1296. (e) Mordant, C.; Dunkelmann, P.; Ratovelomanana-Vidal, V.; Genêt, J.-P. Eur. J. Org. Chem. 2004, 3017. (f) Mordant, C.; Reymond, S.; Ratovelomanana-Vidal, V.; Genêt, J.-P. Tetrahedron 2004, 60, 9715. (g) Labeeuw, O.; Phansavath, P.; Genêt, J.-P. Tetrahedron: Asymmetry 2004, 15, 1899. (h) Mordant, C.; Reymond, S.; Tone, H.; Lavergne, D.; Touati, R.; Ben Hassine, B.; Ratovelomanana-Vidal, V.; Genêt, J.-P. Tetrahedron 2007, 63, 6115. (i) Tone, H.; Buchotte, M.; Mordant, C.; Guittet, E.; Ayad, T.; Ratovelomanana-Vidal, V. Org. Lett. 2009, 11, 1995. (j) Prevost, S.; Gauthier, S.; Cano de Andrade, M. C.; Mordant, C.; Touati, R.; Lesot, P.; Savignac, P.; Ayad, T.; Phansavath, P.; Ratovelomanana-Vidal, V.; Genêt, J.-P. Tetrahedron: Asymmetry 2010, 21, 1436. (k) Cartigny, D.; Püntener, K.; Ayad, T.; Scalone, M.; Ratovelomanana-Vidal, V. Org. Lett. 2010, 12, 3788.

(21) Prévost, S.; Ayad, T.; Phansavath, P.; Ratovelomanana-Vidal, V. Adv. Synth. Catal. 2011, 353, 3213.

(22) (a) Makino, K.; Goto, T.; Hiroki, Y.; Hamada, Y. Angew. Chem. Int. Ed. 2004, 43, 882. (b) See also:Hamada, Y. Chem. Rec. 2014, 14, 235.

(23) (a) Duprat de Paule, S.; Champion, N.; Ratovelomanana-Vidal, V.; Genêt, J.-P.; Dellis, P. French Patent 2830254, 2001; WO 03029259, 2003 (b) Duprat de Paule, S.; Jeulin, S.; Ratovelomanana-Vidal, V.; Genêt, J.-P.; Champion, N.; Dellis, P. Eur. J. Org. Chem. 2003, 1931. (c) Duprat de Paule, S.; Jeulin, S.; Ratovelomanana-Vidal, V.; Genêt, J.-P.; Champion, N.; Deschaux, G.; Dellis, P. Org. Process Res. Dev. 2003, 7, 399. (d) Jeulin, S.; Duprat de Paule, S.; Ratovelomanana-Vidal, V.; Genêt, J.-P.; Champion, N.; Dellis, P. Proc. Natl. Acad. Sci. U.S.A. 2004, 101, 5799. (e) Jeulin, S.; Champion, N.; Dellis, P.; RatovelomananaVidal, V.; Genêt, J.-P. Synthesis 2005, 3666.

(24) Yamagata, T.; Tadaoka, H.; Nagata, M.; Hirao, T.; Kataoka, Y.; Ratovelomanana-Vidal, V.; Genet, J.-P.; Mashima, K. Organometallics 2006, 25, 2505.

(25) Echeverria, P. G.; Férard, C.; Cornil, J.; Guérinot, A.; Cossy, J.; Phansavath, P.; Ratovelomanana-Vidal, V. Synlett 2014, 2761.

(26) Echeverria, P.-G.; Prévost, S.; Cornil, J.; Férard, C.; Reymond, S.; Guérinot, A.; Cossy, J.; Ratovelomanana-Vidal, V.; Phansavath, P. Org. Lett. 2014, 16, 2390.

(27) Magnus, N. A.; Astleford, B. A.; Laird, D. L. T.; Maloney, T. D.; McFarland, A. D.; Rizzo, J. R.; Ruble, J. C.; Stephenson, G. A.; Wepsiec, J. P. J. Org. Chem. 2013, 78, 5768.

(28) Li, X.; Tao, X.; Ma, X.; Li, W.; Zhao, M.; Xie, X.; Ayad, T.; Ratovelomanana-Vidal, V.; Zhang, Z. Tetrahedron 2013, 69, 7152.

(29) Tao, X.; Li, W.; Li, X.; Xie, X.; Zhang, Z. Org. Lett. 2013, 15, 72.

(30) Tao, X.; Li, W.; Ma, X.; Li, X.; Fan, W.; Zhu, L.; Xie, X.; Zhang, Z. J. Org. Chem. 2012, 77, 8401.

(31) Huang, X.-F.; Zhang, S.-Y.; Geng, Z.-C.; Kwok, C.-Y.; Liu, P.; Li, H.Y.; Wang, X.-W. Adv. Synth. Catal. 2013, 355, 2860.

(32) Liu, C.; Xie, J.-H.; Li, Y.-L.; Chen, J.-Q.; Zhou, Q.-L. Angew. Chem. Int. Ed. 2013, 52, 593.

(33) Lin, H.; Xiao, L.-J.; Zhou, M.-J.; Yu, H.-M.; Xie, J.-H.; Zhou, Q.-L. Org. Lett. 2016, 18, 1434.

(34) Wang, D.-S.; Chen, Q.-A.; Lu, S.-M.; Zhou, Y.-G. Chem. Rev. 2012, 112, 2557.

(35) Shi, L.; Ye, Z.-S.; Cao, L.-L.; Guo, R.-N.; Hu, Y.; Zhou, Y.-G. Angew. Chem. Int. Ed. 2012, 51, 8286.

(36) Doering, W. E.; Young, R. W. J. Am. Chem. Soc. 1950, 72, 631.

(37) Hashiguchi, S.; Fujii, A.; Takehara, J.; Ikariya, T.; Noyori, R. J. Am. Chem. Soc. 1995, 117, 7562. 
(38) Schwink, L.; Ireland, T.; Püntener, K.; Knochel, P. Tetrahedron: Asymmetry 1998, 9, 1143.

(39) Murata, K.; Okano, K.; Miyagi, M.; Iwane, H.; Noyori, R.; Ikariya, T. Org. Lett. 1999, 1, 1119.

(40) Wu, Y.; Geng, Z.; Bai, J.; Zhang, Y. Chin. J. Chem. 2011, 29, 1467.

(41) (a) Xu, F.; Zacuto, M. J.; Kohmura, Y.; Rosen, J.; Gibb, A.; Alam, M.; Scott, J.; Tschaen, D. Org. Lett. 2014, 16, 5422. (b) Chung, J. Y. L.; Scott, J. P.; Anderson, C.; Bishop, B.; Bremeyer, N.; Cao, Y.; Chen, Q.; Dunn, R.; Kassim, A.; Lieberman, D.; Moment, A. J.; Sheen, F.; Zacuto, M. J. Org. Process Res. Dev. 2015, 19, 1760.

(42) For a recent review, see: Zhang, Y.; Farrants, H.; Li, X. Chem. Asian J. 2014, 9, 1752.

(43) Liu, Z.; Shultz, C. S.; Sherwood, C. A.; Krska, S.; Dormer, P. G.; Desmond, R.; Lee, C.; Sherer, E. C.; Sherer, E. C.; Shpungin, J.; Cuff, J.; Xu, F. Tetrahedron Lett. 2011, 52, 1685.

(44) Seashore-Ludlow, B.; Villo, P.; Häcker, C.; Somfai, P. Org. Lett. 2010, 12, 5274.

(45) Seashore-Ludlow, B.; Villo, P.; Somfai, P. Chem. Eur. J. 2012, 18, 7219.

(46) Seashore-Ludlow, B.; Saint-Dizier, F.; Somfai, P. Org. Lett. 2012, 14, 6334.

(47) Perez, M.; Echeverria, P. G.; Martinez-Arripe, E.; Ez Zoubir, M.; Touati, R.; Zhang, Z.; Genêt, J. P.; Phansavath, P.; Ayad, T.; Ratovelomanana-Vidal, V. Eur. J. Org. Chem. 2015, 5949.

(48) Echeverria, P. G.; Cornil, J.; Férard, C.; Guérinot, A.; Cossy, J.; Phansavath, P.; Ratovelomanana-Vidal, V. RSC Adv. 2015, 5, 56815.

(49) Bai, J.; Miao, S.; Wu, Y.; Zhang, Y. Chin. J. Chem. 2011, 29, 2476.

(50) Fang, Z.; Wills, M. J. Org. Chem. 2013, 78, 8594.

(51) Echeverria, P.-G.; Férard, C.; Phansavath, P.; RatovelomananaVidal, V. Catal. Commun. 2015, 62, 95.

(52) Monnereau, L.; Cartigny, D.; Scalone, M.; Ayad, T.; Ratovelomanana-Vidal, V. Chem. Eur. J. 2015, 21, 11799.

(53) Rast, S.; Modec, B.; Stephan, M.; Mohar, B. Org. Biomol. Chem. 2016, 14, 2112.

(54) Son, S.-M.; Lee, H.-K. J. Org. Chem. 2013, 78, 8396.

(55) Kumaraswamy, G.; Narayanarao, V.; Shanigaram, P. Tetrahedron 2015, 7, 8960
(56) Kumaraswamy, G.; Narayana Murthy, A.; Narayanarao, V.; Vemulapalli, S. P. B.; Bharatam, J. Org. Biomol. Chem. 2013, 11, 6751.

(57) Son, S.-M.; Lee, H.-K. J. Org. Chem. 2014, 79, 2666.

(58) Geng, Z.; Wu, Y.; Miao, S.; Shen, Z.; Zhang, Y. Tetrahedron Lett. 2011, 52, 907.

(59) Bisset, A. A.; Dishington, A.; Jones, T.; Clarkson, G. J.; Wills, M. Tetrahedron 2014, 70, 7207.

(60) Steward, K. M.; Gentry, E. C.; Johnson, J. S. J. Am. Chem. Soc. 2012, 134, 7329; corrigendum: J. Am. Chem. Soc. 2015, 137, 3715.

(61) Steward, K. M.; Corbett, M. T.; Goodman, C. G.; Johnson, J. S. J. Am. Chem. Soc. 2012, 134, 20197; corrigendum: J. Am. Chem. Soc. 2015, 137, 3991.

(62) Goodman, C. G.; Do, D. T.; Johnson, J. S. Org. Lett. 2013, 15, 2446.

(63) Villacrez, M.; Somfai, P. Tetrahedron Lett. 2013, 54, 5266.

(64) Corbett, M. T.; Johnson, J. S. J. Am. Chem. Soc. 2013, 135, 594.

(65) Bromhead, L. J.; Visser, J.; McErlean, C. S. P. J. Org. Chem. 2014, $79,1516$.

(66) Chen, T.; Ye, Q.; Zhao, Q.; Liu, G. Org. Lett. 2015, 17, 4972.

(67) Foubelo, F.; Yus, M. Chem. Rec. 2015, 15, 907.

(68) Ros, A.; Magriz, A.; Dietrich, H.; Ford, M.; Fernández, R.; Lassaletta, J. M. Adv. Synth. Catal. 2005, 347, 1917.

(69) Uematsu, N.; Fujii, A.; Hashiguchi, S.; Ikariya, T.; Noyori, R. J. Am. Chem. Soc. 1996, 118, 4916.

(70) Kang, S.; Han, J.; Lee, E. S.; Choi, E. B.; Lee, H. K. Org. Lett. 2010, $12,4184$.

(71) Han, J.; Kang, S.; Lee, H. K. Chem. Commun. 2011, 47, 4004.

(72) Lee, H.; Kang, S.; Choi, E. B. J. Org. Chem. 2012, 77, 5454.

(73) Kim, J. A.; Seo, Y. J.; Kang, S.; Han, J.; Lee, H. K. Chem. Commun. 2014, 50, 13706.

(74) For the influence of the $\mathrm{HCO}_{2} \mathrm{H} / \mathrm{Et}_{3} \mathrm{~N}$ ratio, see: (a) Miyagi, M.; Takehara, J.; Collet, S.; Okano, K. Org. Process Res. Dev. 2000, 4, 346. (b) Zhang, J.; Blazecka, P. G.; Bruendl, M. M.; Huang, Y. J. Org. Chem. 2009, 74, 1411. (c) Zhou, X.; Wu, X.; Yang, B.; Xiao, J. J. Mol. Catal. A: Chem. 2012, 357, 133.

(75) Seo, Y. J.; Kim, J. A.; Lee, H. K. J. Org. Chem. 2015, 80, 8887. 